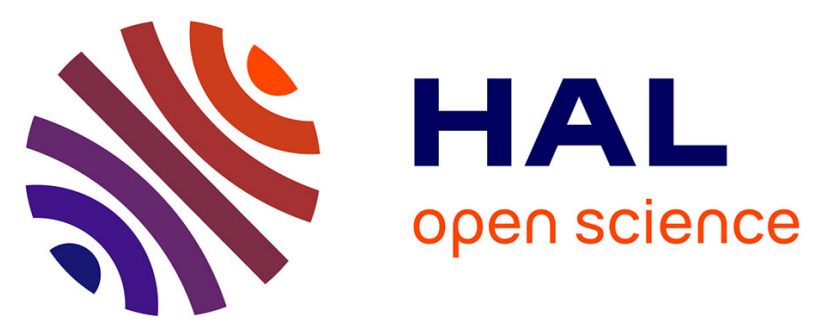

\title{
The seasonal cycle of atmospheric CO 2: A study based on the NCAR Community Climate Model (CCM2)
}

\author{
D. J. Erickson Iii, P. Rasch, P. Tans, P. Friedlingstein, P. Ciais, E. \\ Maier-Reimer, K. Six, C. Fischer, S. Walters
}

\section{- To cite this version:}

D. J. Erickson Iii, P. Rasch, P. Tans, P. Friedlingstein, P. Ciais, et al.. The seasonal cycle of atmospheric CO 2: A study based on the NCAR Community Climate Model (CCM2). Journal of Geophysical Research: Atmospheres, 1996, 101 (D10), pp.15079-15097. 10.1029/95JD03680 . hal-02923800

\section{HAL Id: hal-02923800 \\ https://hal.science/hal-02923800}

Submitted on 28 Oct 2020

HAL is a multi-disciplinary open access archive for the deposit and dissemination of scientific research documents, whether they are published or not. The documents may come from teaching and research institutions in France or abroad, or from public or private research centers.
L'archive ouverte pluridisciplinaire HAL, est destinée au dépôt et à la diffusion de documents scientifiques de niveau recherche, publiés ou non, émanant des établissements d'enseignement et de recherche français ou étrangers, des laboratoires publics ou privés. 


\title{
The seasonal cycle of atmospheric $\mathrm{CO}_{2}$ : A study based on the NCAR Community Climate Model (CCM2)
}

\author{
D. J. Erickson III, ${ }^{1}$ P. J. Rasch, ${ }^{2}$ P. P. Tans, ${ }^{3}$ P. Friedlingstein, ${ }^{1,4}$ P. Ciais, ${ }^{5}$ \\ E. Maier-Reimer, ${ }^{6}$ K. Six,${ }^{6}$ C. A. Fischer,${ }^{1}$ and S. Walters, ${ }^{1}$
}

\begin{abstract}
A global three-dimensional atmospheric model, the NCAR CCM2 general circulation model, has been adapted to study the hourly to yearly variability of $\mathrm{CO}_{2}$ in the atmosphere. Features of this CCM2-based model include high spatial resolution $\left(28^{\circ} \times 2.8^{\circ}\right.$ latitude/ longitude), 18 vertical levels, a 15-min time step, and an explicit, nonlocal atmospheric boundary layer parameterization. The surface source/sink relationships used include exchange with the ocean, the terrestrial biosphere, biomass burning, and fossil fuel release of $\mathrm{CO}_{2}$. The timing and magnitude of the model seasonal cycle are compared to observational data for 28 sites. The seasonal cycle of atmospheric $\mathrm{CO}_{2}$ is generally well predicted by the model for most of the northern hemisphere, but estimates of the amplitude of the seasonal cycle in the southern hemisphere are overpredicted. To address this aspect more rigorously, we have used the monthly surface ocean $p \mathrm{CO}_{2}$ maps created by the Max-Planck-Hamburg ocean general circulation model to asses the ocean seasonality on the atmospheric surface $\mathrm{CO}_{2}$ seasonality. The globally averaged interhemispheric gradient in atmospheric $\mathrm{CO}_{2}$ concentrations, as complited with the chosen source/sink distributions, is a factor of two too high compared to data, and selected longitudinal bands may be up to $50 \%$ higher than the zonal mean. The high temporal resolution of this model allows the infrequent yet real extrema in atmospheric $\mathrm{CO}_{2}$ concentrations to be captured. The vertical attenuation of the seasonal cycle of atmospheric $\mathrm{CO}_{2}$ is well simulated by the boundary layer/free troposphere interaction in the model in the northern hemisphere. Conversely, an increasing amplitude of the seasonal cycle aloft is found in the midlatitude southern hemisphere indicating interhemispheric transport effects from north to south. We use two different models of the terrestrial biosphere to examine the influence on the computed seasonal cycle and find appreciable differences, especially in continental sites. A global three-dimensional chemical transport model is used to assess the production of $\mathrm{CO}_{2}$ from the oxidation of $\mathrm{CO}$ throughout the volume of the atmosphere. We discuss these $\mathrm{CO}+\mathrm{OH} \rightarrow$ $\mathrm{CO}_{2}+\mathrm{H}$ results within the context of inverse model approaches to ascertaining the global and regional source/sink patterns of $\mathrm{CO}_{2}$. Deficiencies in the model output as compared to observational data are discussed within the context of guiding future research.
\end{abstract}

\section{Introduction}

It is clear from experimental evidence that the atmospheric concentration of $\mathrm{CO}_{2}$ has increased from $\sim 280 \mathrm{ppm}$ to $\sim 350$ ppm since the industrial revolution started about 1800 [Keeling et al., 1976; Raynaud et al., 1993]. One of the many aspects of the carbon cycle that is at present not sufficiently quantified is how and where the roughly $50 \%$ of the total anthropogenic $\mathrm{CO}_{2}$ released to the atmosphere has been absorbed by sinks on the Earth surface. There have been arguments put forth for oceanic uptake as well as increased carbon storage in the terrestrial biosphere [Bolin, 1960; Broecker et al., 1979; Tans et al., 1990; Quay et al., 1992; Melillo et al., 1993]. One of the most important constraints on the various global three-dimensional numerical simulations of the atmospheric $\mathrm{CO}_{2}$ cycle is the inter-hemispheric gradient [Denning, 1994]. Since most 2-D and three-dimensional

Copyright 1996 by the American Geophysical Union.

Paper number 95JD03680. 0148-0227/96/95JD-03680\$09.00 atmospheric models tend to overpredict the interhemispheric gradient, it has been suggested that there may be a "missing" sink in the northem hemisphere surface boundary flux conditions.

Here, we describe a global three-dimensional atmospheric $\mathrm{CO}_{2}$ model based on the semi-Lagrangian transport (SLT) code in the NCAR (National Center for Atmospheric Research) community climate model, version 2 (CCM2). The main emphasis of this paper will be to introduce the salient aspects of the SLT/CCM2 transport model and compare the model predictions with atmospheric $\mathrm{CO}_{2}$ observations [e.g. Fung et al., 1983, Denning et al., 1995]. We compare the phasing and amplitude of the model seasonal cycle of atmospheric $\mathrm{CO}_{2}$ with the National Oceanic and Atmospheric Administration/ Climate Monitoring and Diagnostics Laboratory (NOAA/CMDL) observations at 28 sites distributed globally [Conway et al., 1988; Thoning et al., 1989] and aircraft measurements over Cape Grim, Tasmania [Pearman and Beardsmore, 1984] and Sendai, Japan [Tanaka et al., 1987]. We examine two treatments each of the ocean and terrestrial biosphere exchange of $\mathrm{CO}_{2}$ with the atmosphere. 


\section{Model Description}

The transport of moisture and tracers is done in CCM2 by using a three-dimensional "shape-preserving" semiLagrangian transport formalism [Rasch and Williamson, 1990a; Williamson and Rasch, 1989]. The transport scheme was originally developed for the transport of water vapor in a general circulation model [Rasch and Williamson 1990b; 1991]. More recently, it has been succesfully used for the simulation of stratospheric aerosol transport [Boville et al., 1992], for the transport of ${ }^{14} \mathrm{C}$ and the transport of CFCs in troposphere [Hartley et al. 1994]. We performed detailed tests of the mass conservation of $\mathrm{CO}^{2}$ and found that mass was conserved to within $1 \%$ over 5 years. The F-11 tracer experiments compare reasonably well with the Atmospheric Lifetime Experiment/Global Atmospheric Gases Experiment (ALE/GAGE) observational data with respect to seasonal cycle amplitudes, variability, and year-to-year atmospheric accumulation [Hartley et al., 1994]. The shape-preserving transport algorithm can maintain very sharp gradients without introducing overshoorts or undershoots and diffuses only at the smallest scales of the model.

The planetary boundary layer (PBL) parameterization of Holtslag and Boville [1993] is a nonlocal scheme based on the work of Troen and Mahrt [1986], and Holtslag et al. [1990]. The parameterization diagnoses the boundary layer height and uses a prescribed profile of diffusivities below this level. The parameterization includes the typical down gradient diffusion as well as a less typical nonlocal transport term within the convective boundary layer (sometimes called a countergradient transport term). Above the PBL a local vertical diffusion scheme is used. A parameterization of momentum flux divergence produced by stationary gravity waves arising from flow over orography is included, following McFarlane [1987]. A simple mass flux scheme developed by Hack (1993) is used to represent all types of moist convection.

The cloud fraction and cloud albedo parameterizations are a generalization of those of Slingo [1987]. The solar tadiative heating is computed using a delta-Eddington parameterization with 18 spectral bands [Briegleb, 1992]. Sea surface temperatures are specified by linear interpolation between the climatological monthly mean values of Shea et al. [1990]. Surface fluxes are calculated with stability dependent transfer coefficients between the surface and the first model level, detailed by Holtslag and Boville [1993]. Both diurnal and annual cycles are included. Radiative heating rates are calculated periodically and held constant between calculations. Absorptivities and emissivities are calculated every 24 hours. Radiative heating rates are calculated every 1.5 hours. The land temperature is calculated by a four-layer diffusion model with soil heat capacities specified for each layer to capture the major observed climatological cycles. The land has specified soil hydrologic properties [Hack et al., 1994].

\section{Surface Boundary Fluxes}

The uptake and release of atmospheric $\mathrm{CO}_{2}$ with various surface boundary carbon reservoirs imparts a strong signal on observed atmospheric $\mathrm{CO}_{2}$ concentrations on time scales ranging from days to years. In our calculations we have selected the four main boundary flux conditions that are presently thought to be important for simulating the variability of atmospheric $\mathrm{CO}_{2}$ on daily to yearly timescales. The terrestrial biosphere is one of the most important components of the Earth system that influences atmospheric $\mathrm{CO}_{2}$ concentrations on daily to seasonal timescales. The ocean is thought to be important in the global $\mathrm{CO}_{2}$ budget on seasonal to yearly timescales. Land use change, especially biomass burning in developing countries, may contribute significantly to the observed increase in atmospheric $\mathrm{CO}_{2}$ concentrations and we use a source term that has a weak seasonality. Fossil fuel combustion is the main single anthropogenic source of atmospheric $\mathrm{CO}_{2}$ and we use a source that is without a seasonal cycle. The deforestation and terrestrial biosphere fluxes are constructed from monthly means that are interpolated to give daily values. Figure 1 shows the globally integrated net fluxes from each of our initial four source/sink parameterizations: fossil fuel and deforestation are both positive over the seasonal cycle; the ocean is a net sink over the seasonal cycle and the terrestrial biosphere imparts the majority of the variability of the seasonal cycle and sums to roughly zero over the seasonal cycle. Table 1 shows the annual integrated net sources. Note that the sum of the global fluxes does not add up to the atmospheric $\mathrm{CO}_{2}$ increase that has been observed over the last decade, namely, 3.0 Gt (1012

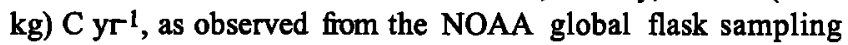
network. The main emphasis of this work, however, is the seasonal cycle of atmospheric $\mathrm{CO}_{2}$ and we are not concerned here with decadel time scale changes in the mean atmospheric $\mathrm{CO}_{2}$ concentration. We use the four surface boundary $\mathrm{CO}_{2}$

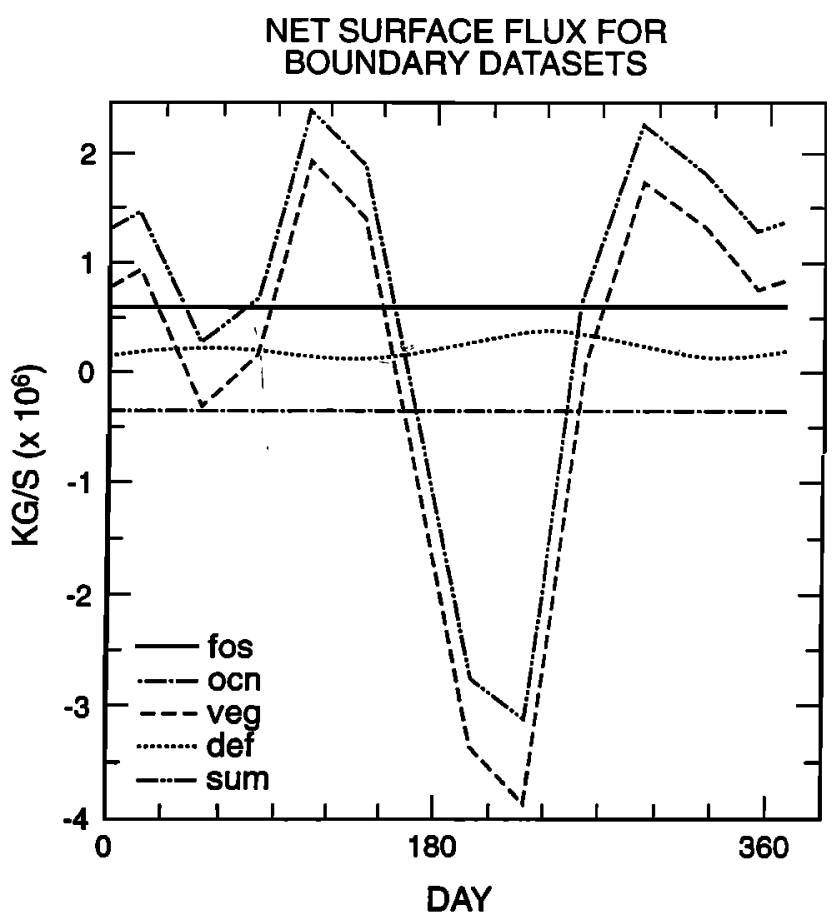

Figure 1. The net surface fluxes used in the initial version of the model. The fossil fuel tracer is always positive and is assumed to be invariant over the seasonal cycle. The land use change (deforestation) tracer is also always positive and has a slight seasonality. The ocean is a net sink for atmospheric $\mathrm{CO}_{2}$ and is also assumed to be constant over the seasonal cycle. Note that the largest temporal forcing on the atmospheric $\mathrm{CO}_{2}$ budget is from the terrestrial biosphere. Units of $10^{6} \mathrm{~kg} \mathrm{CO}_{2} \mathrm{~s}^{-1}$. 
Table 1. Annual Magnitude of the Global Source/Sink Terms Used in Model Runs

\begin{tabular}{lcc}
\hline Source/Sink & Time Resolution & Annual C Flux as $\mathrm{CO}_{2}, \mathrm{~kg} \mathrm{C} \mathrm{yr}^{-1}$ \\
\hline Fossil fuel $^{\mathrm{a}}$ & annual & $5.3 \times 10^{12}$ \\
Ocean $^{\mathrm{b}}$ & annual & $-2.7 \times 10^{12}$ \\
Oceanc $^{\mathrm{c}}$ & monthly & $-.22 \times 10^{12}$ \\
Land use changed $^{\mathrm{d}}$ & monthly & $2.1 \times 10^{12}$ \\
Vegetatione $^{\mathrm{N}}$ & monthly & $-.003 \times 10^{12}$ \\
Vegetation $^{\mathrm{f}}$ & monthly & $-0.00 \times 10^{12}$ \\
\hline
\end{tabular}

a Marland and Rotty [1984].

${ }^{b}$ Broecker et al. [1986] $p \mathrm{CO}_{2}$ field with a ${ }^{14} \mathrm{C}$ consistent transfer velocity. cMax-Planck-Institute für Meteorlogie-Hamburg (MPI-H) threedimensional ocean model.

Including Biomass Burning, Mueller [1992].

eFung et al. [1987].

fFriedlingstein et al. [1992].

flux estimates summarized in Figure 1 in our initial model runs and compare and contrast the results from these runs with additional model runs employing the Friedlingstein et al. [1992] terrestrial biosphere model and the Max-Planck Institute (MPI-Hamburg) ocean model.

\subsection{Terrestrial Biosphere}

The atmosphere exchanges carbon with the terrestrial biosphere on a variety of time scales, one of the most prominent being the seasonal cycle. In the phase 1 calculations we have used the monthly global grids described by Fung et al. [1987]. These global source/sink terms sum to roughly zero for the annual cycle. In addition, note that each element of the terrestrial source/sink grid sums to approximately zero over the annual cycle, Table 1 . The overall seasonal cycle of all source/sink terms is clearly dominated by variation in atmosphere-terrestrial biosphere $\mathrm{CO}_{2}$ exchange. In a section below we compare the model runs of the Fung et al. [1987] sources with those of Friedlingstein et al. [1992] with particular emphasis on the amplitude and phasing of the seasonal cycle at middle-high latitudes of the northern hemisphere.

\subsection{Ocean}

The ocean has long been known to influence the atmospheric concentrations of many trace gas species. The distribution of the partial pressure of $\mathrm{CO}_{2}\left(\mathrm{pCO}_{2}\right)$ in the global surface ocean is one of the important factors in modeling air-sea $\mathrm{CO}_{2}$ transfer (Sarmiento and Sundquist, 1992). In these calculations we have used the annual mean $p \mathrm{CO}_{2}$ grid of Broecker et al. [1986] and a monthly model estimate of $p \mathrm{CO}_{2}$ produced by the Max-Planck-Institut fuir Meteorologie, Hamburg, ocean GCM. The $p \mathrm{CO}_{2}$ grid has been converted to a flux map via the application of a ${ }^{14} \mathrm{CO}_{2}$ consistent transfer velocity, as described in Equation (1)

$$
\mathrm{F}=\mathrm{K}_{\mathrm{w}}\left[p \mathrm{CO}_{2}^{*}-p \mathrm{CO}_{2 \mathrm{so}}\right]
$$

where $F$ is the net flux and may have units of umol cm-2 $\mathrm{h}^{-1}$ when $K_{\mathrm{w}}$ is the transfer velocity $\left(\mathrm{cm} \mathrm{h}^{-1}\right), p \mathrm{CO}_{2}{ }^{*}$ is the partial pressure of $\mathrm{CO}_{2}$ in surface sea water in equilibrium with an atmospheric $\mathrm{CO}_{2}$ wet mixing ratio of $350 \mathrm{ppm}$ ( $\mu$ molecules $\mathrm{cm}^{-3}$ ) and $p \mathrm{CO}_{2 \mathrm{so}}$ is the measured or modeled $\mathrm{CO}_{2}$ partial pressure in surface ocean seawater (umol $\mathrm{cm}^{-3}$ ). Note that $\mathrm{pCO}_{2}{ }^{*}$ is a nonlinear solubility-related function of surface ocean temperature, salinity, total inorganic carbon, and alkalinity [Weiss, 1974]. It is straightforward to see that the sense of the air-sea flux is determined by the deviations of $p \mathrm{CO}_{2 \text { so }}$ from $p \mathrm{CO}_{2}{ }^{*}$. When the surface ocean is undersaturated with respect to the atmosphere, the flux of $\mathrm{CO}_{2}$ is into the ocean; when the ocean is supersaturated with respect to the atmosphere, the converse is true. It is important to note that there is substantial uncertainty in the global distribution of both $p \mathrm{CO}_{2 \text { so }}$ and $K_{\mathrm{w}}$ [Etcheto and Merlivat, 1988; Erickson, 1993]. The global mean transfer velocity has been made consistent with the observed oceanic uptake of ${ }^{14} \mathrm{C}$ produced by nuclear testing.

The partial pressure of $\mathrm{CO}_{2}$ in surface ocean waters $\left(p \mathrm{CO}_{2}\right)$ is a complicated function of several different physical, chemical, and biological processes. It is important to note that several recent experimental studies have observed much variability in the surface ocean $\mathrm{CO}_{2}$ content [Watson et al., 1991; Wong and Chan, 1991]. While it is currently believed that the main source term that influences the seasonal cycle of atmospheric $\mathrm{CO}_{2}$ is the terrestrial biosphere, in the southern hemisphere there may be an important seasonal forcing due to the ocean. This will be the topic addressed when we compare and contrast the atmospheric $\mathrm{CO}_{2}$ results obtained from using two different ocean treatments.

\subsection{Land Use Change/Biomass Burning}

The release of carbon to the atmosphere from land use changes, mostly conversion of tropical forest to cropland or pasture (including biomass burning), has been accounted for by using the global distribution of these processes as described by Mueller [1992]. The total annual flux is estimated as $2.1 \mathrm{Gt} \mathrm{C}$ per year. Note that in the time series of the four different sources over the annual cycle (Figure 1) there is a slight seasonality in the land use change emissions, largely related to the amount of precipitation over the tropical forest regions. Clearly, most biomass burning is occurring in tropical regions of developing countries such as Brazil [Woodwell et al., 1983]. The small negative values represent those areas that have been altered by mankind and are presently regrowing as cultivated crops or new forest growth.

\subsection{Fossil Fuel}

The flux of $\mathrm{CO}_{2}$ to the atmosphere associated with the combustion of fossil fuel is an important component of the contemporary cycle of atmospheric $\mathrm{CO}_{2}$ [Keeling, et al., 1976; Marland and Rotty, 1984]. Based on experimental and modeling evidence, the observed increase in atmospheric $\mathrm{CO}_{2}$ is primarily due to the addition of $\sim 5 \mathrm{Gt} \mathrm{C}$ (as $\mathrm{CO}_{2}$ ) $\mathrm{yr}^{-1}$ being added by the fossil fuel source [Revelle and Suess, 1957]. Here, we use a source function that is invariant in time over the annual cycle. The annual flux that we have used in this work is $5.3 \mathrm{Gt} \mathrm{C}$ (as $\mathrm{CO}_{2}$ ) $\mathrm{yr}^{-1}$ [Rotty, 1987a, b]. The source term is known to be somewhat seasonal in character [Marland and Rotty. 1984]; however, this variability is thought to be of the order of $10-20 \%$ and we do not include the monthly variability in these first numerical experiments with the model.

\section{Model Diagnostics}

The model has been run for 6 years with the output data archived every 12 hours. We have selected years 5 and 6 as the years which we will use to diagnose the model via 

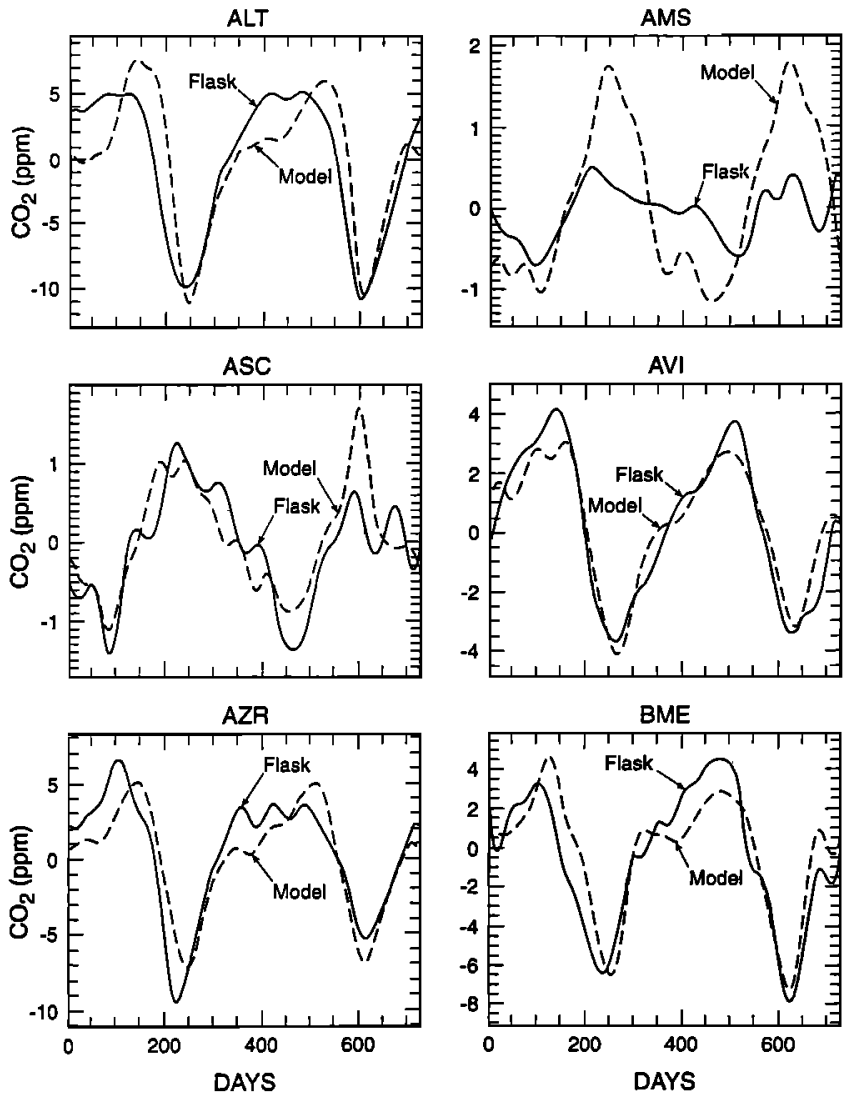

Figure 2. The CCM2-based carbon cycle model predicted atmospheric $\mathrm{CO}_{2}$ concentrations compared with the National Oceanic and Atmospheric Administration/Climate Monitoring and Diagnostics Laboratory (NOAA/CMDL) observational data for 28 sites around the world. See Table 2 for location information. Day 1 corresponds to January 1.

comparison with observational data. The seasonal cycles in atmospheric $\mathrm{CO}_{2}$ mixing ratios at a variety of observational stations are compared with the model predictions. The computed interhemispheric gradient in atmospheric $\mathrm{CO}_{2}$ and the phasing and amplitude of the seasonal cycle as a function of altitude are also discussed within the context of the observations.

\subsection{Seasonal Cycle Simulations}

We have selected 28 stations with which to objectively compare the model. The CMDL data used for comparison with the model output for years 5-6 are from 1989 and 1990. The observational data years selected for comparison to the model were chosen to be relatively free of obvious climate "anomalies" such as El Nino or Pinatubo and display a more or less "climatological" character that is appropriate for examination of seasonal cycles. In some cases the years used were different from 1989 and 1990 due to the incompleteness of the observational data during this period. In those cases, the nearest 2-year time series at the station was used in the model-data comparison. Figure 2 shows the model-data comparison at the 28 different sites. We used a low-pass digital filter with a frequency cutoff for detrending of 0.5 cycles $\mathrm{yr}^{-1}$ for both the data and the model output. The smoothing was done in a similar way with the cutoff frequency set to $18.25 \mathrm{yr}^{-1}$. We then subtract the local mean from the two treated data sets to get Figure 2. The general characteristics of both data and observations are larger $\left(>5 \mathrm{ppm} \mathrm{CO}_{2}\right)$ seasonal amplitudes of $\mathrm{CO}_{2}$ in the northern hemisphere and smaller $(<5$ ppm $\mathrm{CO}_{2}$ ) in the southern hemisphere.

Table 2 shows the amplitude of the modeled and observed seasonal cycle for each of the 28 stations plotted as function of latitude and summarized in Figure 3. The seasonal cycle amplitudes in the northern hemisphere are much larger than in the southern hemisphere. The Cape Meares, Oregon, Station $\left(45^{\circ} \mathrm{N}, 124^{\circ} \mathrm{W}\right)$, shows the influence of sector sampling on the subsequently derived seasonal cycle. The observations are restricted at this station to conditions when the winds are from off the Pacific so as to sample a marine 'background' condition. This explains why the summer 'drawdown' of atmospheric $\mathrm{CO}_{2}$ due to the increased activity of the terrestrial biosphere as computed by the model does not appear so strongly in the observational record. This is a common feature of several of the experimental sites. In southern hemisphere regions the model-computed seasonal cycles are overestimated as compared to the observations. In a section below, we use the seasonally varying surface ocean $p \mathrm{CO}_{2}$ field of the MPI-H ocean general circulation model to drive the atmospheric model. In section 4.1 we will discusss in detail the seasonal cycles at selected geographically representative stations.
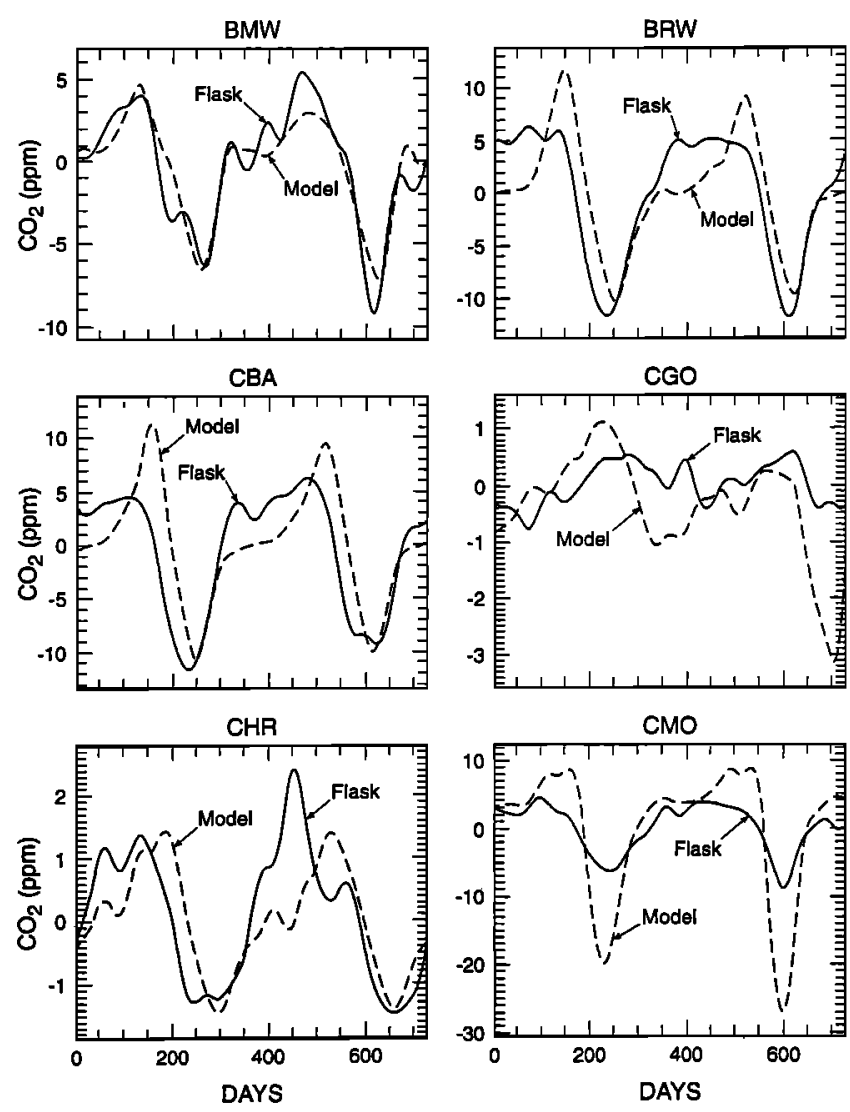

Figure 2. (continued) 

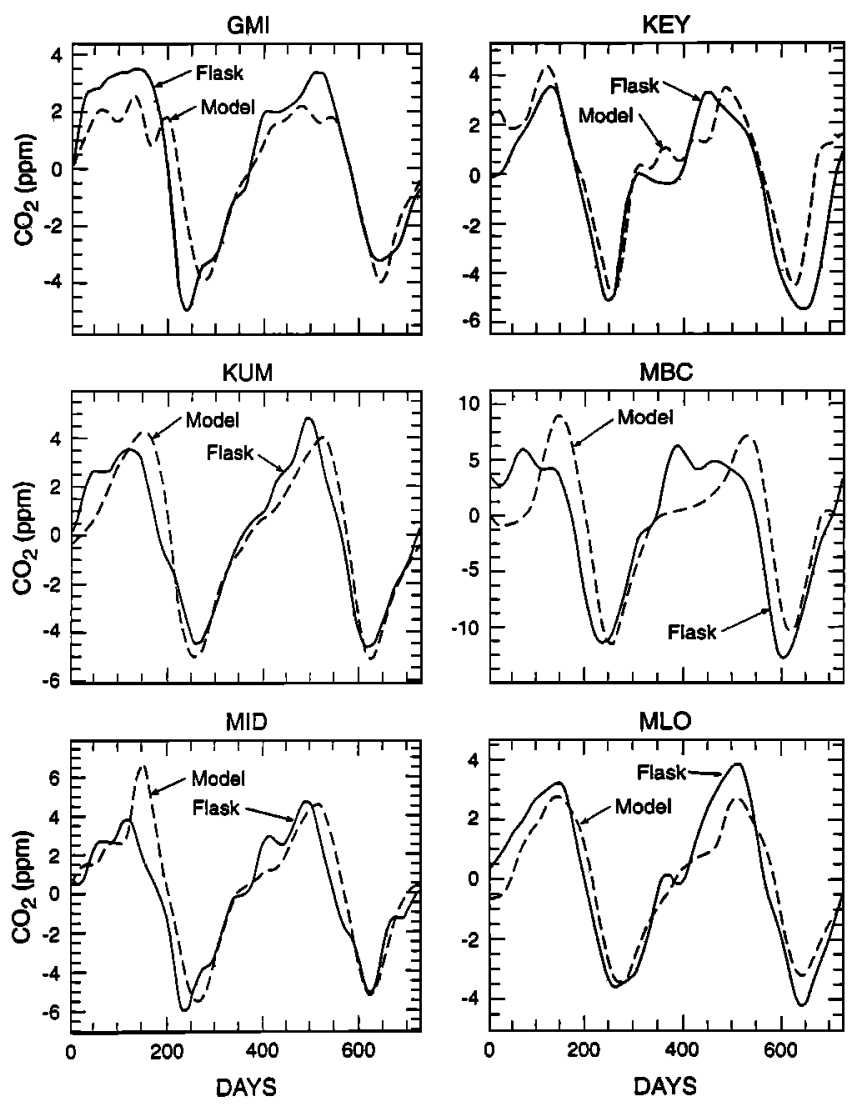

Figure 2. (continued)

4.1.1. Mauna Loa. Figure 4 shows the model-observation comparison, smoothed and detrended, for three annual cycles at Mauna Loa $\left(19.5^{\circ} \mathrm{N}, 155.6^{\circ} \mathrm{W}\right)$. Here, to facilitate the interpretation of climatological seasonal cycle, we smooth by averaging every 7 days and then fit a cubic spline to the resulting points. This removes much of the shorter timescale variability present in Figure 2 . The seasonal cycle is dominated by the uptake and release of $\mathrm{CO}_{2}$ by the terrestrial biosphere, resulting in a seasonal cycle (peak-to-peak amplitude) of about $6 \mathrm{ppm}$ (Table 2). The phasing of the seasonal cycle is in reasonable agreement with the observations, with several stations being offset by a few weeks to a month. Note that in Figure 2, using the Fast Fourier Transform approach to get the amplitude of the seasonal cycle, the computed amplitudes are somewhat higher than in this analysis. The relative difference between the model and the observations is still roughly $1 \mathrm{ppm} \mathrm{CO}_{2}$. This points out that great care must be taken in using a variety of statistical methods to analyze both model output and data, especially when comparing results between diverse research groups.

An important test of model variability is the ability of the model to replicate the deviations of individual events from some long-term mean. The model is run at a 15 -min time step and we choose to save a three-dimensional model 'realization' every 12 hours. Figure 5 a shows the high-frequency residuals from a smooth seasonal cycle for the CCM2 model run, as computed from a cubic spline curve fit, and Figure $5 \mathrm{~b}$ shows the residuals for the NOAA/CMDL observations. The vast majority of the residuals are within $1 \mathrm{ppm}$ in the model run as well as in the data, which is encouraging. In addition, there appears to be a clear seasonality in the model residuals that appears to some extent in the data. This seasonality has enhanced variability in the late winter-spring seasons that may be related to transport issues [Harris and Kahl, 1990; Harris et al., 1992]. This 12-hour timescale variability indicates the possibility of up to 3-4 ppm variability in atmospheric $\mathrm{CO}_{2}$ concentrations that are related to the local synoptic scale meteorology. Indeed, a power spectrum of the model output as well as the observational data show significant power in the 3 to 4-day band.

4.1.2. Bermuda. Bermuda $\left(33^{\circ} \mathrm{N}, 89^{\circ} \mathrm{W}\right)$ is generally downwind from the North American continent, which has strong terrestrial biosphere and fossil fuel emission signals. The seasonal cycle of the model and data are presented in Figure 6. The detrended model predictions are in reasonable agreement with the observations with the amplitude of the seasonal cycle averaging about $8.7 \mathrm{ppm}$. The observational data show a somewhat anomalous spring-summer minimum in 1991 that does not appear in the model. This could be related to interannual variability in the source/sink terms in the real world that are not included in the present model formulation. Note that the fall 'bump' in the observational data is also replicated by the model and is related to a seasonal release of carbon from the terrestrial biosphere as well as an enhanced transport of fossil fuel $\mathrm{CO}_{2}$ during this time period. This
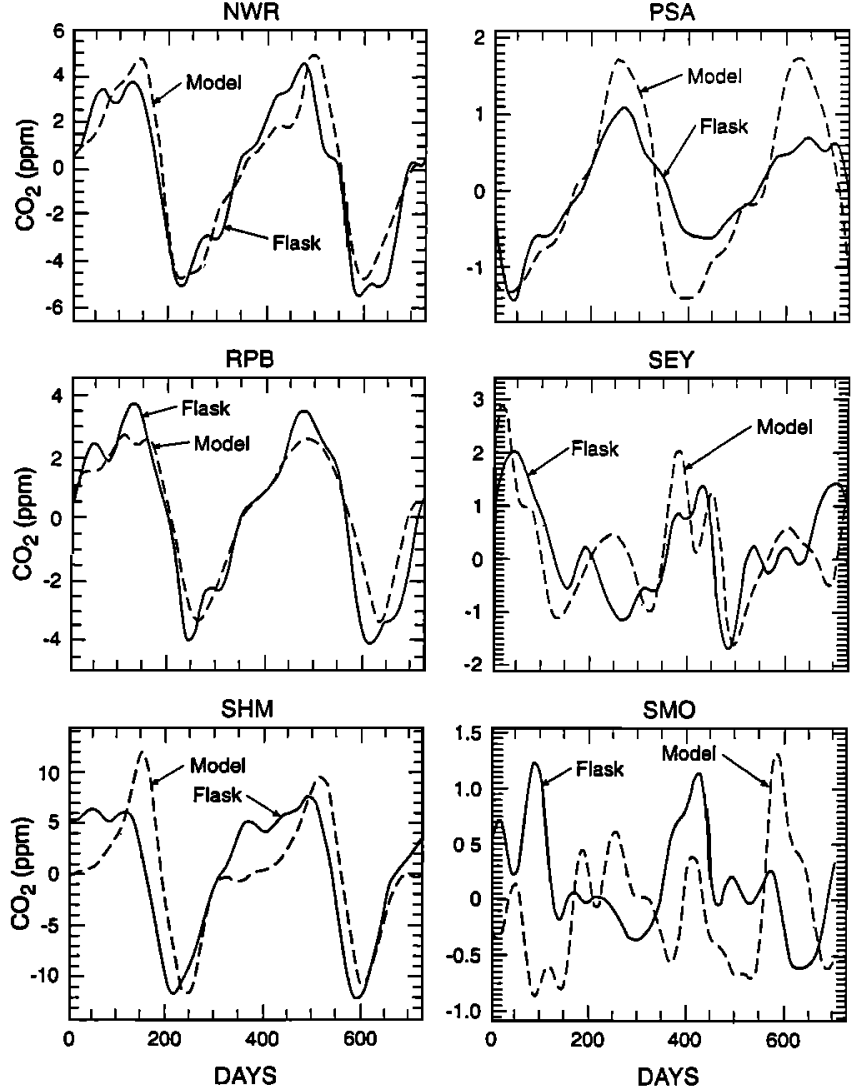

Figure 2. (continued) 

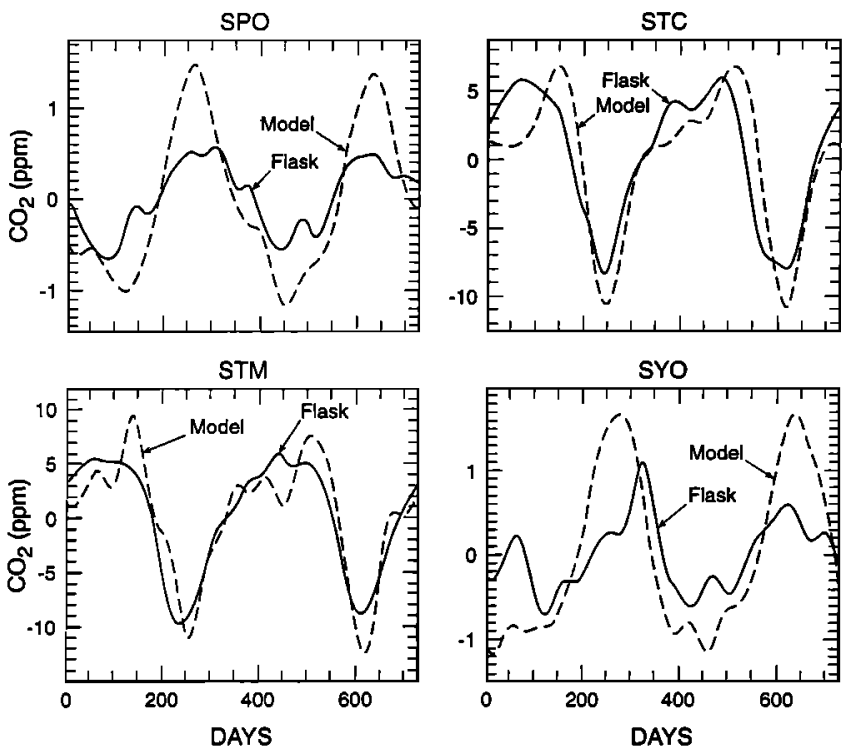

Figure 2. (continued)

aspect of the model-data comparison is discussed in greater detail in a section below.

During the third year of the model-data comparison it is obvious that the observational data show a much stronger drawdown of atmospheric $\mathrm{CO}_{2}$ during the spring-summer period than occurs in the model or the preceding two years of the observations. We intentionally include this feature in our analysis to emphasize that the interannual variability of the real Earth system is large. We speculate that the drawdown of atmospheric $\mathrm{CO}_{2}$ at Bermuda during this particular year is related to the changes in the surface sourcesink relationships that year as opposed to changes in atmospheric transport.

An interesting and significant aspect of this new model is the possibility of modeling the high-frequency variability of atmospheric $\mathrm{CO}_{2}$ concentrations. Bermuda allows us to look closely at this aspect of the model. Figure 7 shows the observed, weekly variation in atmospheric $\mathrm{CO}_{2}$ concentration as measured at the Bermuda (west) station. In addition to the pronounced seasonal cycle there are several 'outliers' that are several ppm less than the mean trend. Back trajectories calculated for these occurrences suggest a circulation pattern in the summer whereby a parcel of air is advected rapidly from the photosynthetically active regions of midlatitude northern hemisphere regions to Bermuda, thereby preserving some of low $\mathrm{CO}_{2}$ signature caused by photosynthesis. Figure 8 shows the model predictions for Bermuda and the infrequent yet real instances where parcels of $\mathrm{CO}_{2}$-depleted air are arriving at Bermuda during summer clearly stand out. Therefore the model is capturing these high frequency variations that exist in the experimental data. Also note the 'positive' outliers in the data, mostly in fall and winter, and model predictions that represent the short timescale advection of 'polluted' air parcels from the industrialized regions of North America. This kind of detailed analysis of the model performance highlights the importance of using short timescale transport information (hours) in order to interpret certain aspects of the observational record.

Table 2. Comparison of Seasonal Cycle Amplitudes in the Three-Dimensional Model With Observations

\begin{tabular}{|c|c|c|c|c|c|}
\hline Site & Latitude & Longitude & Elevation, m & Model & Observed \\
\hline Alert, & $82^{\circ} 27 \mathrm{~N}$ & $62^{\circ} 31^{\prime} \mathrm{W}$ & 210 & 17.45 & 15.34 \\
\hline Ascension Island & $7^{\circ} 55 ' \mathrm{~S}$ & $14^{\circ} 25^{\prime} \mathrm{W}$ & 54 & 2.51 & 2.25 \\
\hline St. Croix, Virgin Islands & $17^{\circ} 45 \mathrm{~N}$ & $64^{\circ} 45 \mathrm{~W}$ & 3 & 6.60 & 7.46 \\
\hline Azores (Terceira Island) & $38^{\circ} 45 \mathrm{~N}$ & $27^{\circ} 05^{\prime} \mathrm{W}$ & 30 & 12.11 & 12.72 \\
\hline Bermuda (east) & $32^{\circ} 22 \mathrm{~N}$ & $64^{\circ} 39^{\prime} \mathrm{W}$ & 30 & 10.22 & 10.99 \\
\hline Bermuda (west) & $32^{\circ} 16^{\prime} \mathrm{N}$ & $65^{\circ} 53^{\prime} \mathrm{W}$ & 30 & 10.22 & 12.20 \\
\hline Point Barrow, Alaska & $71^{\circ} 19 \mathrm{~N}$ & $156^{\circ} 36^{\prime} \mathrm{W}$ & 30 & 20.20 & 17.40 \\
\hline Cold Bay, Alaska & $55^{\circ} 12 \mathrm{~N}$ & $162^{\circ} 43^{\prime} \mathrm{W}$ & 25 & 17.31 & 16.52 \\
\hline Cape Grim, Tasmania & $40^{\circ} 41^{\prime} \mathrm{S}$ & $144^{\circ} 41^{\prime} \mathrm{E}$ & 94 & 2.29 & 1.15 \\
\hline Christmas Island & $2^{\circ} 00 \mathrm{~N}$ & $157^{\circ} 19^{\prime} \mathrm{W}$ & 3 & 2.83 & 3.39 \\
\hline Cape Meares, Oregon & $45^{\circ} 29 ’ \mathrm{~N}$ & $124^{\circ} 00^{\prime} \mathrm{W}$ & 30 & 30.79 & 11.22 \\
\hline Guam & $13^{\circ} 26 \mathrm{~N}$ & $144^{\circ} 47^{\prime} \mathrm{E}$ & 2 & 6.26 & 7.79 \\
\hline Key Biscayne, Florida & $24^{\circ} 40 \mathrm{~N}$ & $80^{\circ} 12^{\prime} \mathrm{W}$ & 3 & 8.47 & 8.70 \\
\hline Cape Kumukahi, Hawaii & $19^{\circ} 31 \mathrm{~N}$ & $154^{\circ} 49^{\prime} \mathrm{W}$ & 3 & 9.17 & 8.98 \\
\hline Mould Bay, Canada & $76^{\circ} 14 \mathrm{~N}$ & $119^{\circ} 20^{\prime} \mathrm{W}$ & 15 & 18.07 & 17.27 \\
\hline Sand Island, Midway & $28^{\circ} 13 \mathrm{~N}$ & $177^{\circ} 22^{\prime} \mathrm{W}$ & 4 & 10.70 & 10.09 \\
\hline Mauna Loa, Hawaii & $19^{\circ} 32 \mathrm{~N}$ & $155^{\circ} 35^{\prime} \mathrm{W}$ & 3397 & 6.09 & 7.45 \\
\hline Niwot Ridge, Colorado & $40^{\circ} 03 \mathrm{~N}$ & $105^{\circ} 38^{\prime} \mathrm{W}$ & 3749 & 9.70 & 9.59 \\
\hline Palmer Station (Anvers Island) & $64^{\circ} 55^{\prime} \mathrm{S}$ & $64^{\circ} 00^{\prime} \mathrm{W}$ & 10 & 3.13 & 2.03 \\
\hline Ragged Point & $13^{\circ} 10^{\prime} \mathrm{N}$ & $59^{\circ} 26^{\prime} \mathrm{W}$ & 3 & 5.98 & 7.62 \\
\hline Seychelles (Mahe Island) & $4^{\circ} 40^{\prime} \mathrm{S}$ & $55^{\circ} 10^{\prime} \mathrm{E}$ & 3 & 3.66 & 2.99 \\
\hline Shemya Island & $52^{\circ} 43 \mathrm{~N}$ & $174^{\circ} 06^{\prime} \mathrm{E}$ & 40 & 21.74 & 18.99 \\
\hline American Samoa & $14^{\circ} 15^{\prime} \mathrm{S}$ & $170^{\circ} 34^{\prime} \mathrm{W}$ & 3 & 1.91 & 1.66 \\
\hline Amundsen Scott (south pole) & $89^{\circ} 59^{\prime} \mathrm{S}$ & $24^{\circ} 48^{\prime} \mathrm{W}$ & 2810 & 2.47 & 1.14 \\
\hline Ocean Station "C" & $54^{\circ} 00^{\prime} \mathrm{N}$ & $35^{\circ} 00^{\prime} \mathrm{W}$ & 6 & 17.47 & 14.15 \\
\hline Ocean Station "M" & $66^{\circ} 00 \mathrm{~N}$ & $2^{\circ} 00 \mathrm{E}$ & 6 & 19.82 & 15.22 \\
\hline Syowa Station & $69^{\circ} 00 \mathrm{~N}$ & $39^{\circ} 35 \mathrm{E}$ & 11 & 2.65 & 1.44 \\
\hline
\end{tabular}




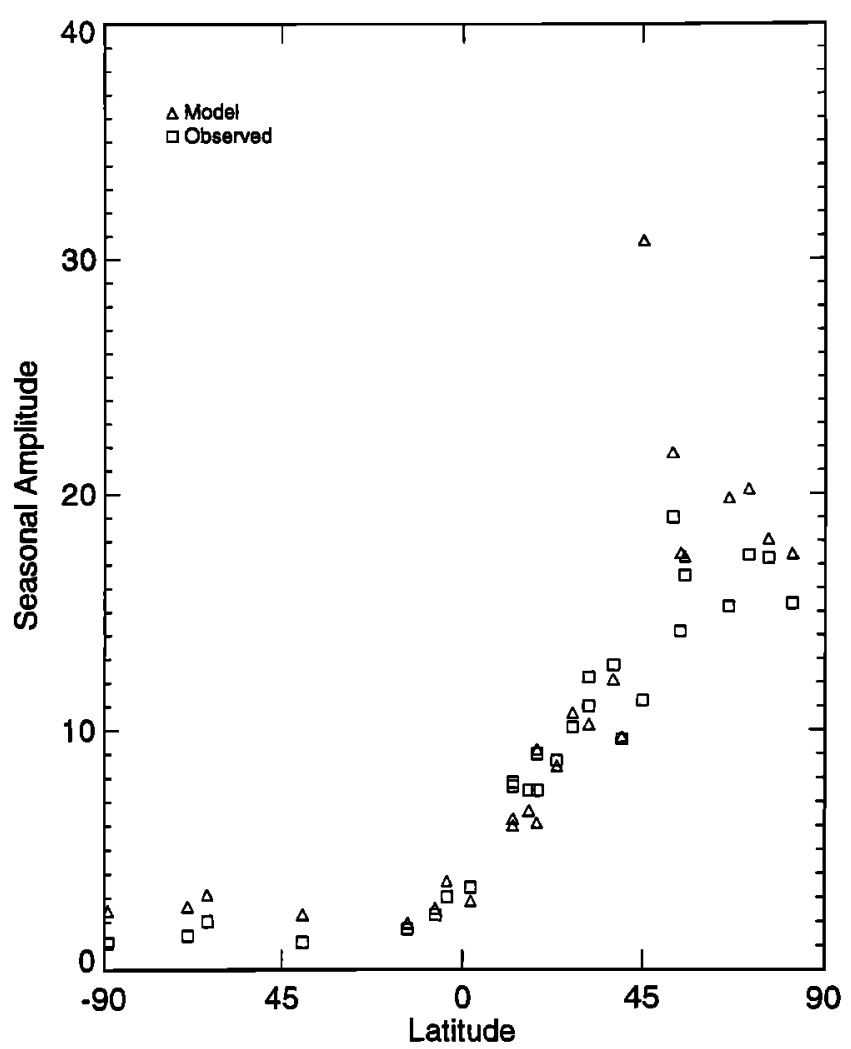

Figure 3. The zonal mean of the amplitude of the seasonal cycle plotted for the 28-station model-data comparison shown in Figure 2. Note the decreasing amplitude of the seasonal cycle from north to south.

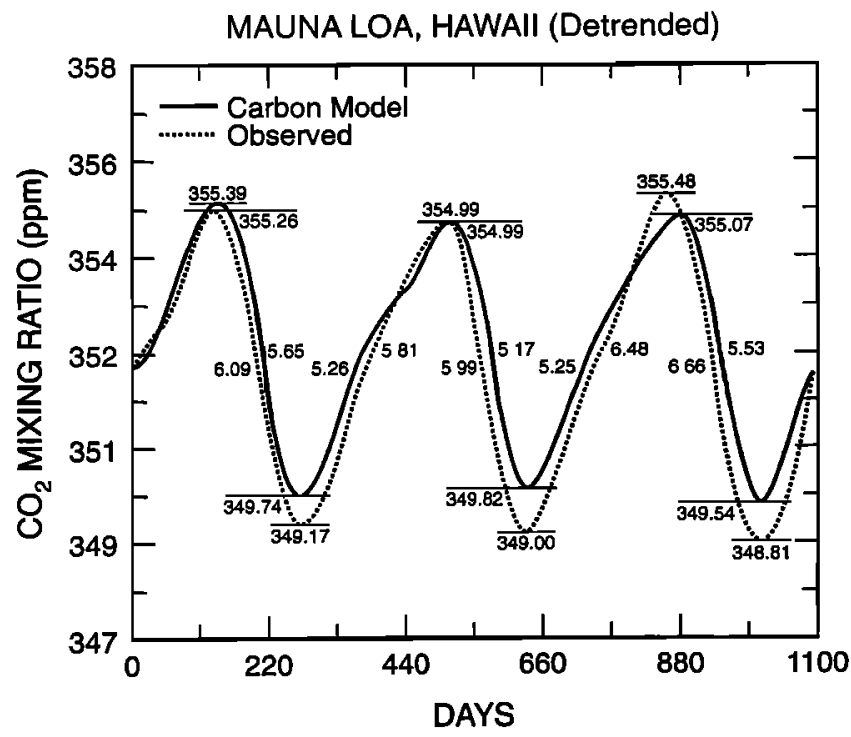

Figure 4. The detrended and smoothed seasonal cycle for 3 years from the model run and the CMDL/NOAA in situ data at Mauna Loa, Hawaii. The model results are from years 4,5 , and 6 of the model integration and the observational data are from 1989, 1990 and 1991. Note that the model and observations agree quite well with respect to the amplitude with the model underestimating the summer drawdown by about $0.7 \mathrm{ppm}$.

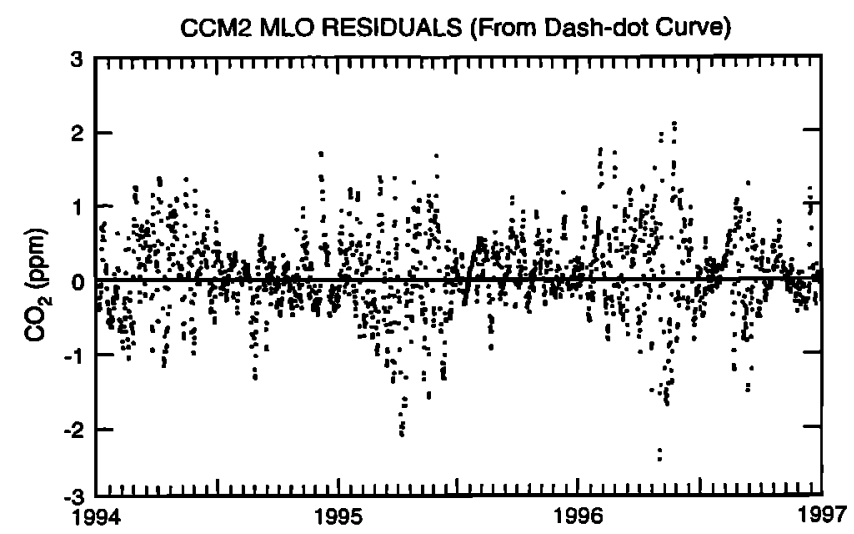

Figure 5a. The residuals of the CCM2 model predicted atmospheric $\mathrm{CO}_{2}$ concentrations for 3 years of model run at Mauna Loa, Hawaii. Note that the model has a clear seasonality in the distribution of residuals with much more variability in the first 6 months of the year.

4.1.3. South Pole. Figure 9 shows the model-data comparisons for the seasonal cycle at the South Pole station, $90^{\circ} \mathrm{S}$. Clearly from this detrended analysis, the amplitude of the model seasonal cycle is roughly a factor of 2 too large compared to the data. The phasing of the seasonal cycle data, however, is good. It is possible that the $\mathrm{CO}_{2}$ sink in the southern oceans is highly seasonal, changing the amplitude of the annual cycle observed at the South Pole and other remote southern hemisphere stations. It is interesting to note that the model tendency to overestimate the seasonal cycle in the southern hemisphere is also observed in the three-dimensional modeling study using observed winds [Keeling et al., 1989a, b; Heimann and Keeling, 1989; Heimann et al., 1989]. In a section below we present a detailed analysis of the individual

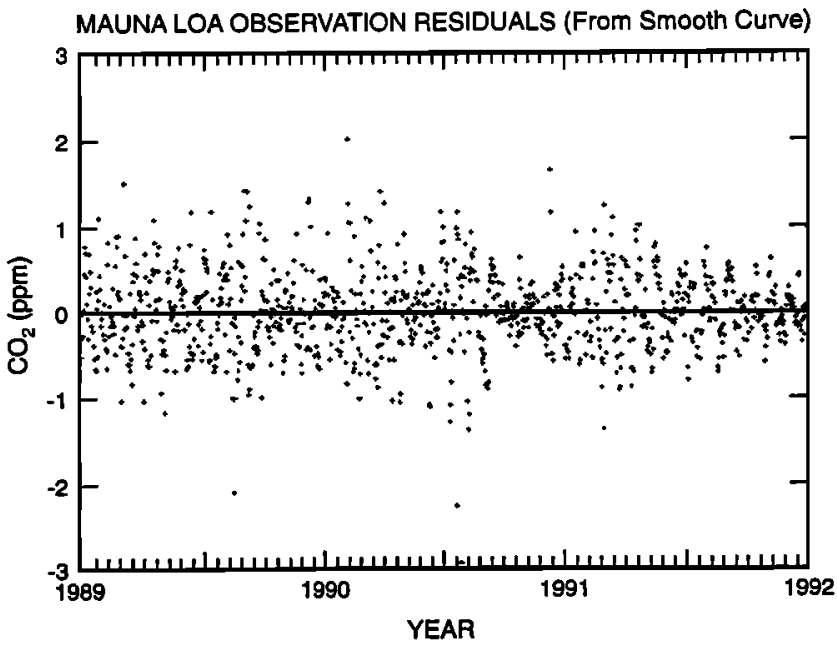

Figure 5b. For comparison with Figure 5a the residuals of the observational atmospheric $\mathrm{CO}_{2}$ concentrations for 3 years at Mauna Loa, Hawaii. Note that the model has a similar seasonality in the residuals as the observations. 


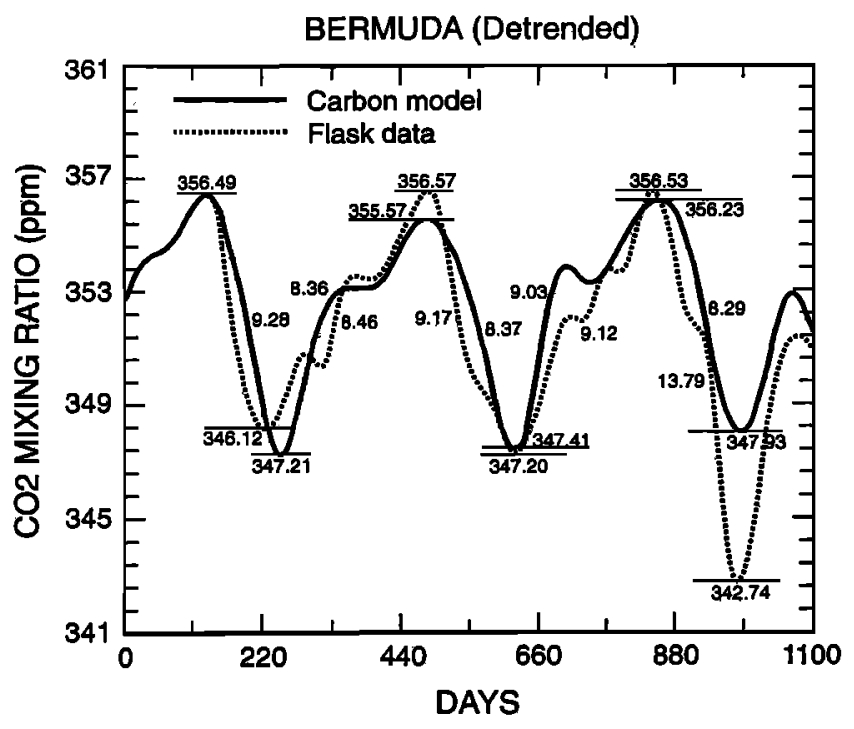

Figure 6. The detrended and smoothed seasonal cycle for 3 years from the model run and the CMDL/NOAA flask data at Bermuda. The model results are from years 4, 5, and 6 of the model integration and the observational data are from 1989, 1990 , and 1991. Note the model and observations agree quite well with respect to the amplitude of the seasonal cycle and that in the third year of the comparison the large $(\sim 5 \mathrm{ppm})$ difference between the model and the data emphasizes the climatological nature of the model forcing as contrasted with the natural variability of the real Earth system.

model component tracers that result in the model-data differences and examine the influence of a seasonally varying ocean source/sink formulation (MPI-Hamburg) upon the computed atmospheric seasonal cycles.

\subsection{Vertical Phasing and Amplitude of Seasonal Cycle}

4.2.1. Mauna Loa and Cape Kumukahi. One of the interesting tests of model performance is how the tracer concentrations vary in the vertical in response to the surface

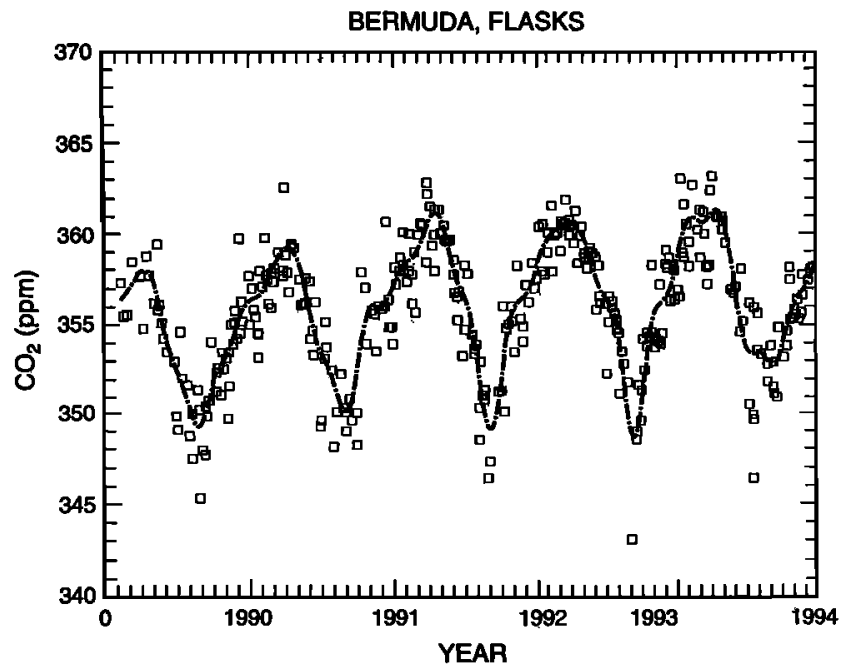

Figure 7. The weekly flask data of the CMDL/NOAA group at Bermuda. Note the very low atmospheric $\mathrm{CO}_{2}$ values that occur once or twice a summer.

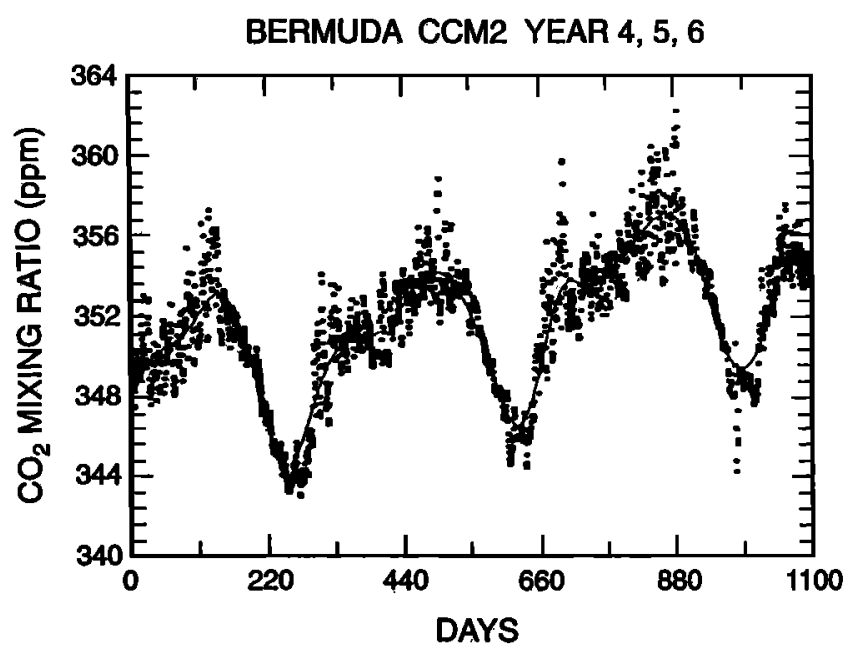

Figure 8. The time series of the 12-hour model predictions for Bermuda. Note that as in Figure 7, there are a few very low atmospheric $\mathrm{CO}_{2}$ values during the summer. This may be interpreted as an indication that parcels of $\mathrm{CO}_{2}$-depleted air may be advected from the North American continent to Bermuda before substantial mixing can occur. The model is capturing this infrequent yet real atmospheric phenomena.

forcings applied [Heimann et al., 1989]. To examine this aspect of our model, we have compared and contrasted the model output for a sea level station, Cape Kumukahi $\left(19.5^{\circ} \mathrm{N}\right.$, $154.8^{\circ} \mathrm{W}$ ), with the Mauna Loa Station at $3400 \mathrm{~m}$. Figures 10a and 10b show the seasonal cycles for both the CMDL observational data and the model output at Cape Kumukahi and Moana Loa. The amplitude of the seasonal cycle of the

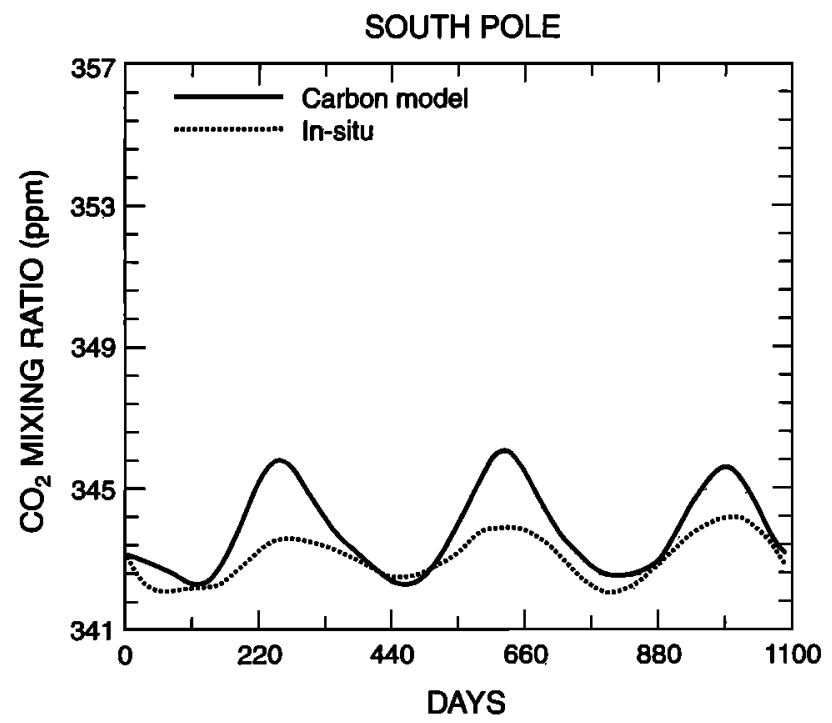

Figure 9. The smoothed and detrended seasonal cycle for 3 years from the model run and the CMDL/NOAA flask data at the south pole. The model results are from years 4,5 , and 6 of the model integration and the observational data are from 1989, 1990, and 1991. Clearly, the model overestimates the amplitude of the seasonal cycle of atmospheric $\mathrm{CO}_{2}$; however, the phasing is quite good. We discuss the results of a atmospheric model run using an alternative ocean forcing in a section above. 


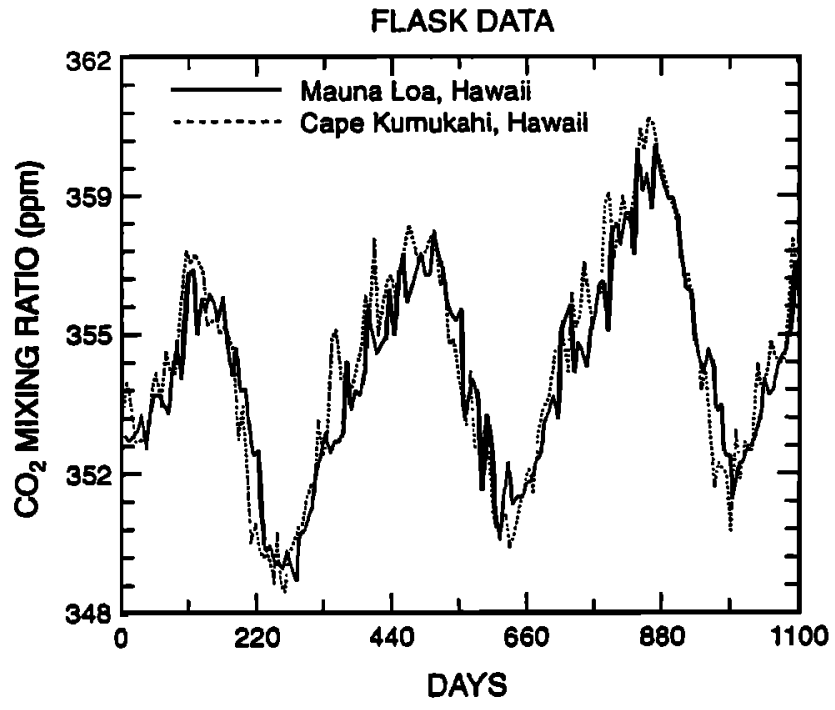

Figure 10a. The seasonal cycle for 3 years from the CMDL/NOAA flask data at Cape Kumukahi, Hawaii $(3 \mathrm{~m}$ above mean sea level (amsl)) and Mauna Loa, Hawaii (3400 m amsl). The observational data are from 1989, 1990, and 1991 . Note that the Cape Kumukahi data always fall slightly to the left of the Mauna Loa data, indicating a phase shift of a few weeks.

model output for Cape Kumukahi is within 0.2 part in 9 of the observed seasonal sycle (Table 2). The CMDL flask data for Cape Kumukahi ( $3 \mathrm{~m}$ above mean sea level (amsl)) and Mauna Loa $(3400 \mathrm{~m}$ amsl) provide some interesting information (Figure 10a). The Cape Kumukahi observational data fall to the left of the Mauna Loa which indicates that the lowerelevation station experiences the terrestrial imprint on the atmospheric $\mathrm{CO}_{2}$ concentrations a few weeks before the middle

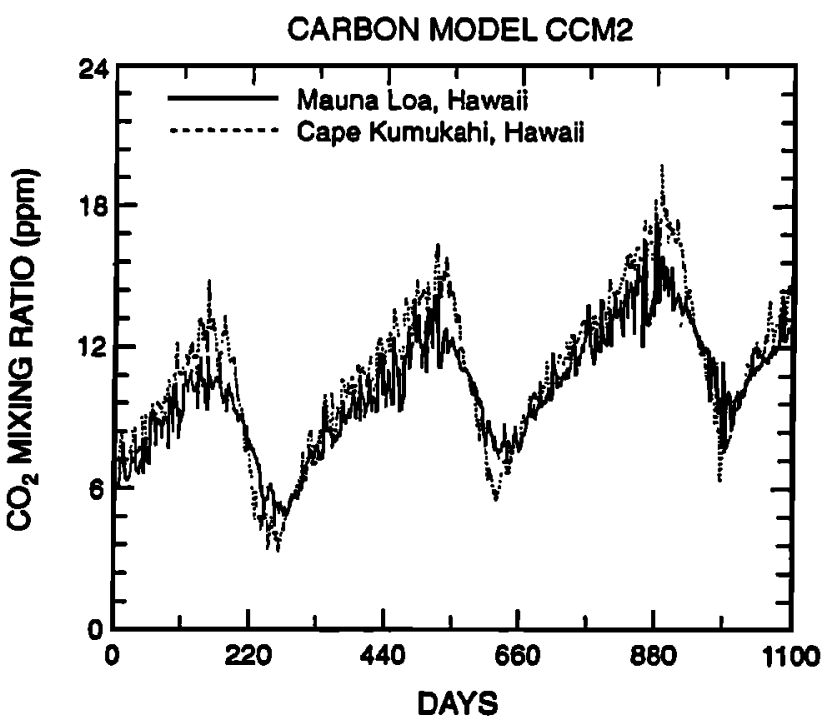

Figure 10b. The seasonal cycle for 3 years from the NCAR CCM2 at Cape Kumukahi, Hawaii (3 $\mathrm{m}$ amsl) and Mauna Loa, Hawaii (3400 $\mathrm{m}$ amsl). For comparison with Figure 10a, note that the Cape Kumukahi model predictions always fall slightly to the left of the Mauna Loa model predictions, similar to the observational data.

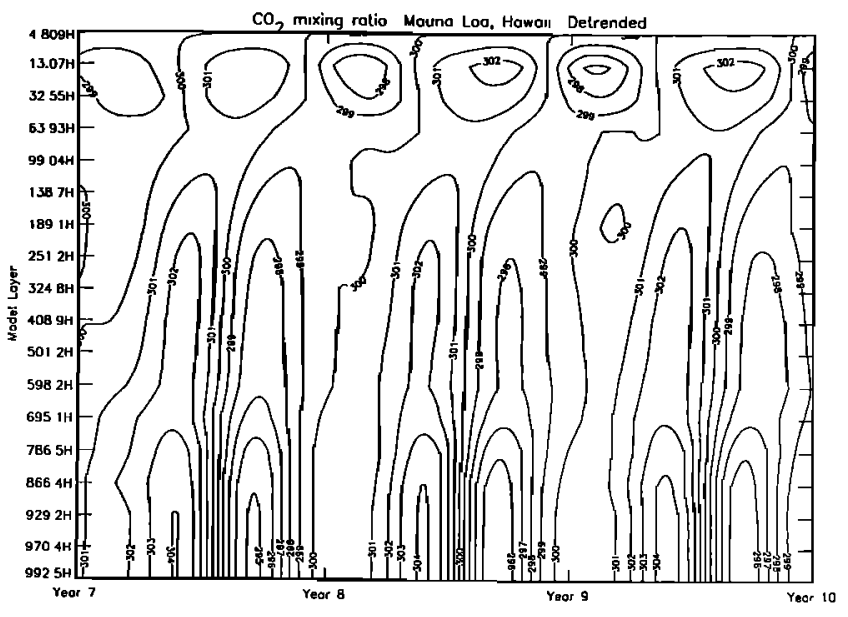

Figure 11. The vertical distribution of atmospheric $\mathrm{CO}_{2}$ concentration, detrended, for 3 years at the model grid point of the Mauna Loa Observatory. Note the general decrease of the amplitude of the seasonal cycle with increasing altitude, except at the top of the model.

troposphere station, Mauna Loa. The amplitude of the seasonal cycle at Cape Kumukahi is also $\sim 25 \%$ larger than the amplitude of the seasonal cycle at Mauna Loa. Figure $10 \mathrm{~b}$ shows the comparison between the Cape Kumukahi Station and the Mauna Loa Station as computed by CCM2. As in the data, the Cape Kumukahi atmospheric $\mathrm{CO}_{2}$ concentrations lead the Mauna Loa concentrations by a few weeks. Also, the amplitude of the seasonal cycle is $-35 \%$ larger at the lowerelevation station, in the same sense as the the observational data. The model is representing the vertical attenuation of the impact of surface forcing quite well. Figure 11 shows the time evolution over 3 model years of the vertical $\mathrm{CO}_{2}$ concentration, detrended, for the location of the Mauna Loa Observatory. Note the decrease in amplitude with increasing altitude with a small increase in seasonality at the top of the model domain.

4.2.2. Sendai, Japan. We have examined the vertical attenuation of the seasonal cycle of $\mathrm{CO}_{2}$ over Sendai, Japan $\left(38^{\circ} \mathrm{N}, 140^{\circ} \mathrm{E}\right)$. Figures $12 \mathrm{a}$ and $12 \mathrm{~b}$ show the detrended model seasonal cycle for 3 years at $\sim 930$ mbar and $\sim 410$ mbar.

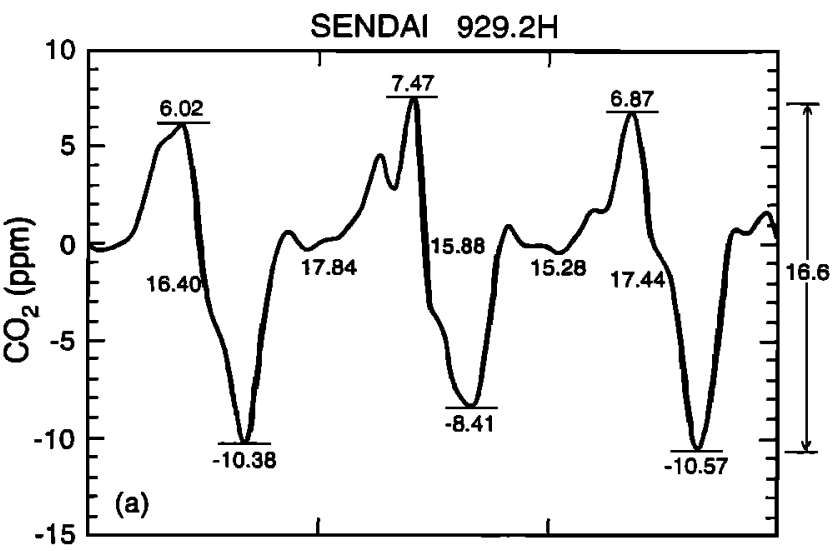

Figure 12a. The detrended model seasonal cycle of atmospheric $\mathrm{CO}_{2}$ at the model surface level for Sendai, Japan. The mean amplitude of the seasonal cycle is $\sim 16.6 \mathrm{ppm} \mathrm{CO}_{2}$. 


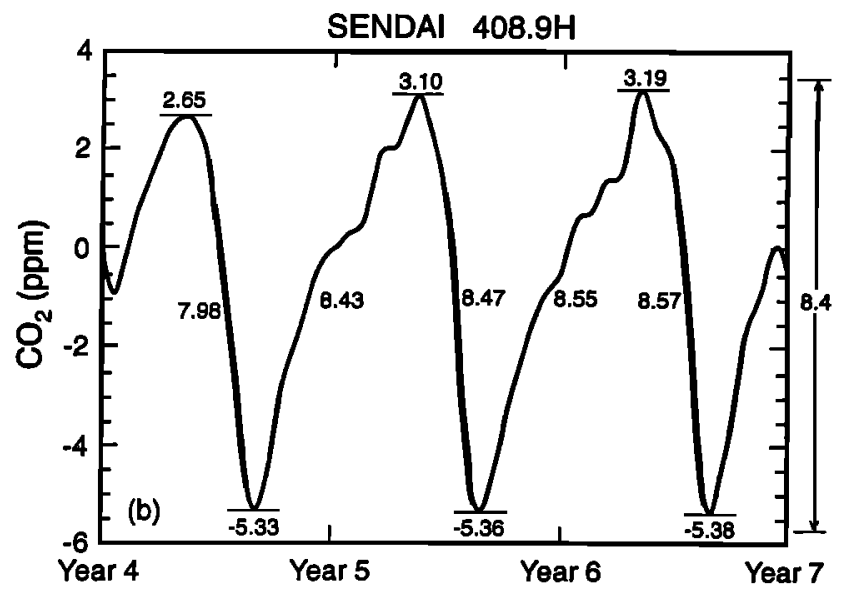

Figure 12b. The detrended model seasonal cycle of atmospheric $\mathrm{CO}_{2}$ at the $\sim 410$-mbar level for Sendai, Japan. The mean amplitude of the seasonal cycle is $\sim 8.4 \mathrm{ppm} \mathrm{CO}_{2}$, roughly a factor of 2 less than at the surface (Figure 12a).

The amplitude of atmospheric $\mathrm{CO}_{2}$ at the surface is roughly $16.6 \mathrm{ppm}$. The small 'shoulders' during the first few months of the year are due to transport processes in the boundary layer interacting with the surface emission patterns. Figure $12 \mathrm{~b}$ shows the detrended seasonal cycle at -410 mbar. The amplitude of the seasonal cycle in atmospheric $\mathrm{CO}_{2}$ is $8.4 \mathrm{ppm}$, roughly a factor of 2 smaller than at the surface station. This is the same trend as seen at the two Hawaii stations. For comparison with some observational data, Tanaka et al. [1987], report seasonal cycle amplitudes in the lowest $2 \mathbf{~ k m}$ of the atmosphere of $\sim 14.2 \mathrm{ppm}$ and $8.0 \mathrm{ppm}$ at $\sim 410 \mathrm{mbar}$. This indicates that the boundary layer proccesses are working adequately near the Asian continent as well as in the remote Pacific, as indicated by the analysis for Mauna Loa.

4.2.3. Cape Grim, Tasmania. The seasonal cycle in the southern hemisphere has been seen to be substantially smaller than in the northern hemisphere, based on both observations and models. At Cape Grim, Tasmania $\left(40^{\circ} \mathrm{S}, 144^{\circ} \mathrm{E}\right)$, Figures $13 \mathrm{a}$ and $13 \mathrm{~b}$ show the detrended model amplitudes for two vertical levels, 930 mbar and 410 mbar. Figures $13 \mathrm{a}$ and $13 \mathrm{~b}$

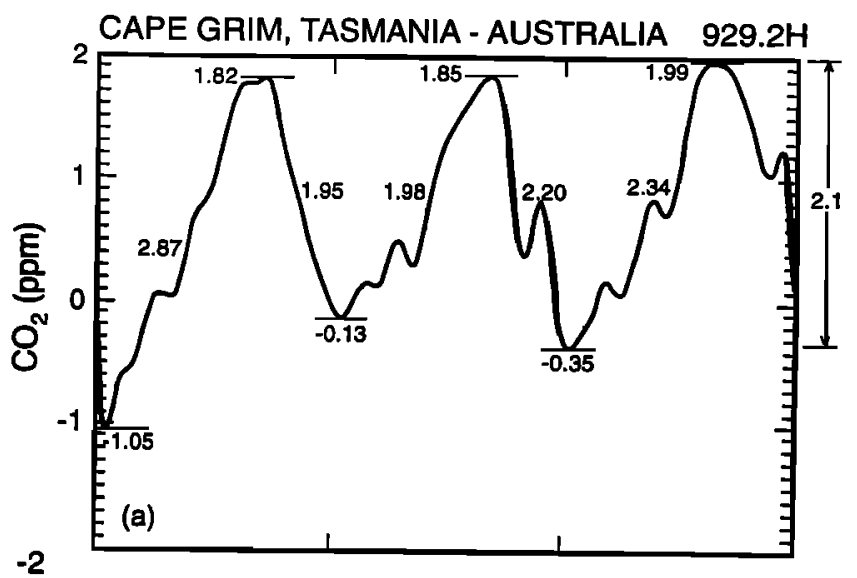

Figure 13a. The detrended seasonal cycle of atmospheric $\mathrm{CO}_{2}$ at the model surface level for Cape Grim, Tasmania. The mean amplitude of the seasonal cycle is $\sim 2.1 \mathrm{ppm} \mathrm{CO}_{2}$.

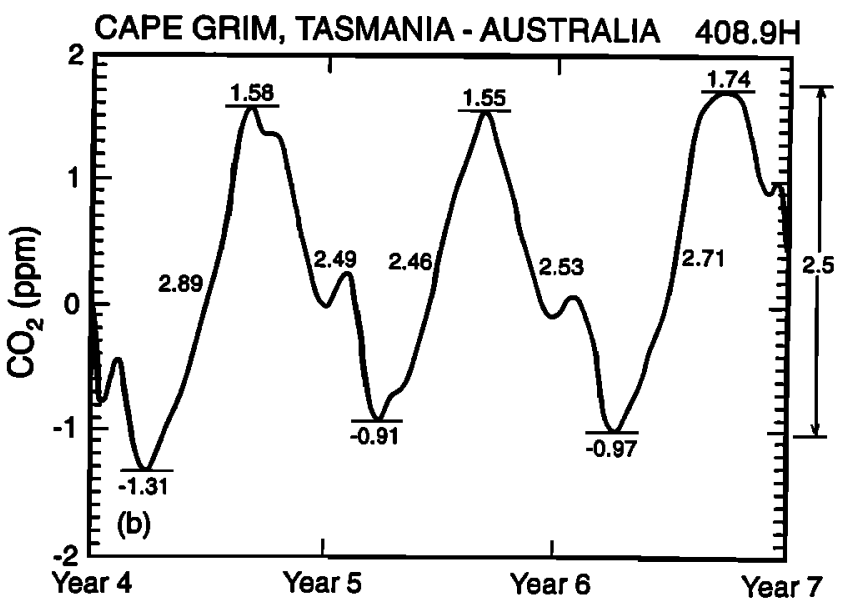

Figure 13b. The detrended seasonal cycle of atmospheric $\mathrm{CO}_{2}$ at the $\sim 410$ mbar level for Cape Grim, Tasmania The mean amplitude of the seasonal cycle is $\sim 2.5 \mathrm{ppm} \mathrm{CO}_{2}$, roughly $20 \%$ greater than at the surface, Figure 13a.

show the seasonal cycle at the surface to be roughly $2.1 \mathrm{ppm}$, whereas at 410 mbar it is actually larger by $\sim 20 \%, 2.5 \mathrm{ppm}$. This is exactly opposite what is observed and modeled at the northern hemisphere sites. This is due to the fact that the transport of northern hemisphere $\mathrm{CO}_{2}$ to the southern hemisphere occurs most efficiently in the middle troposphere, an aspect verified by observational data [Pearman and Beardsmore, 1984] and replicated in the modeling study of Keeling et al. (1989a, b).

4.3. Interhemispheric gradient. The interhemispheric gradient of atmospheric $\mathrm{CO}_{2}$ is closely linked to the magnitude and spatial distributions of the surface source/sink terms. To first order, the large $\sim 5.3 \mathrm{Gt} \mathrm{C}$ (as $\mathrm{CO}_{2}$ ) source to the atmosphere from the combustion of fossil fuels occurs primarily in the northern hemisphere and one would expect the northern hemisphere annual mean $\mathrm{CO}_{2}$ mixing ratio to be higher than the southern hemisphere. However, this expectation should

ZONAL AVERAGES FOR YEARS 4, 5, 6

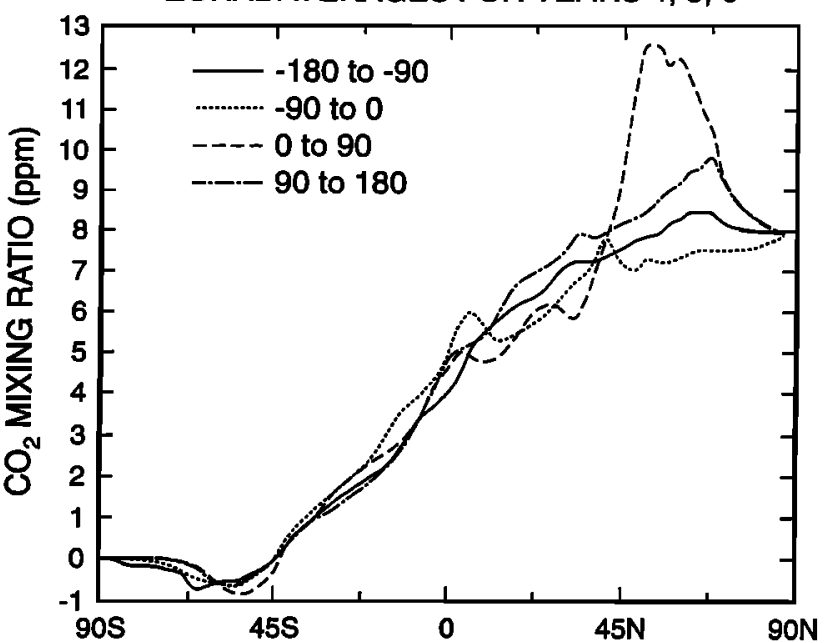

Figure 14. The zonal average of the atmospheric $\mathrm{CO}_{2}$ concentration for four longitudinal bands around the globe. Note that the area that includes Europe is 50\% higher than the other three bands. 


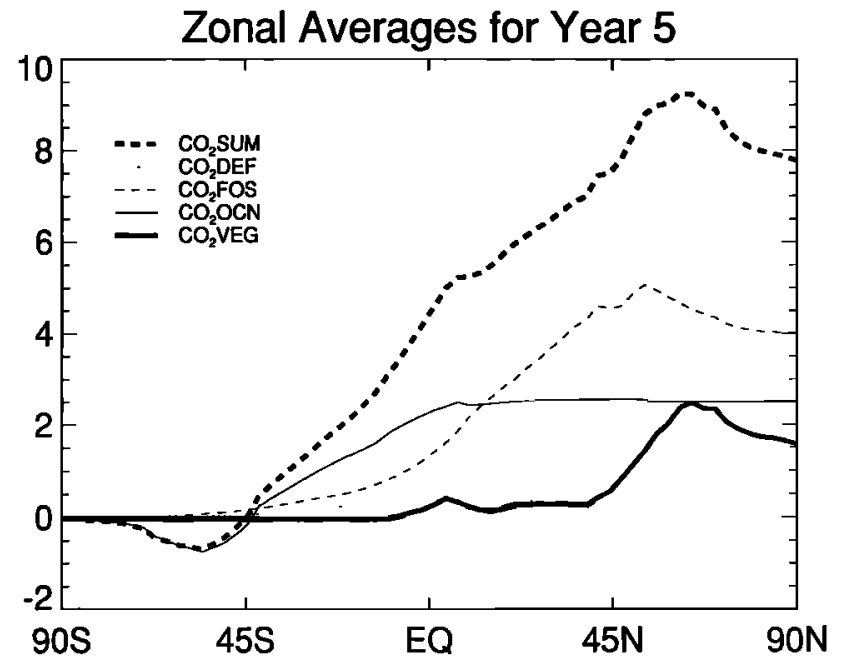

Figure 15. The zonal mean for each of the different carbon cycle tracers. Note the "trapping" of the vegetative tracer in the northern hemisphere resulting in a enhancement of the interhemispheric gradient by $\sim 2.5 \mathrm{ppm}$.

be tempered by the fact that if the terrestrial biosphere reacts to elevated $\mathrm{CO}_{2}$ by enhanced growth, the 'fertilization effect,' the gradient may be somewhat less. That is, since most of the terrestrial biosphere is in the northern hemisphere, should there be a fertilization effect, it would serve to decrease the interhemispheric gradient. The interplay between the $\mathrm{CO}_{2}$ release from fossil fuel combustion and spatial heterogeneity in the $\mathrm{CO}_{2}$ uptake by the terrestrial biosphere and the ocean all play a large role in maintaining the atmospheric $\mathrm{CO}_{2}$ interhemispheric gradient.

We have examined the model-generated interhemispheric gradient in surface level atmospheric $\mathrm{CO}_{2}$ as a function of longitude. Figure 14 shows the interhemispheric gradient for four different longitudinal bands, $0^{\circ}-90^{\circ} \mathrm{W}, 90^{\circ} \mathrm{W}-180^{\circ} \mathrm{W}$, $90^{\circ} \mathrm{E}-180^{\circ} \mathrm{W}$, and $0^{\circ}-90^{\circ} \mathrm{E}$. The mean gradient is about $8 \mathrm{ppm}$, which is a factor of 2 larger than the observational data. It is interesting to note that the gradient is roughly $50 \%$ larger, 12 ppm, for the band encompassing the region from the Greenwich meridian to $90^{\circ} \mathrm{E}$. This aspect of the model predictions emphasizes the need to clearly identify what geographic regions the measured gradients represent and suggests the possibility that a judicious choice of sampling sites as a function of longitude together with atmospheric modeling will better pinpoint the location and nature of important sources and sinks of $\mathrm{CO}_{2}$.

Figure 15 shows the interhemispheric gradient of the four different tracers used in the initial model runs and described in Figure 1. An interesting point is the fact that the terrestrial biosphere tracer creates a net interhemispheric gradient in $\mathrm{CO}_{2}$ $(\sim 2.5 \mathrm{ppm})$ even though there is no net annual mean uptake anywhere in the terrestrial biosphere. This is due to the correlation of interhemispheric transport and the month-tomonth uptake and release of $\mathrm{CO}_{2}$ from the terrestrial biosphere [Enting and Mansbridge, 1987]. The fact that we get a 2.5 ppm $\mathrm{CO}_{2}$ interhemispheric gradient from just the terrestrial biosphere leads us to conclude that in the preindustrial time the gradient may have been in the same sense as today (i.e., northern hemisphere atmospheric $\mathrm{CO}_{2}$ concentrations greater than the southern hemisphere concentrations) but about a factor of 2-3 smaller. The enhanced gradient observed today (4-5 ppm $\mathrm{CO}_{2}$ ) is clearly due to the release of fossil fuel $\mathrm{CO}_{2}$. In order for the ocean to counter this terrestrial biosphereatmospheric transport-related gradient, there would have to be a strong source of $\mathrm{CO}_{2}$ in the southern ocean or a strong sink in the northern hemisphere. This ocean source would have to be sustained over many decades or be as persistent as the gradient imposed by the terrestrial biosphere. We feel that this magnitude of an ocean source would be difficult to sustain and that the preindustrial interhemispheric $\mathrm{CO}_{2}$ gradient may have been of the same sense as the present day but smaller in magnitude. We also conclude that the present-day gradient is indicative of a sink in the northern hemisphere midlatitudes. The estimates of ocean uptake of $\mathrm{CO}_{2}$ cannot account for the 'missing sink,' and we feel that the terrestrial biosphere may where this net uptake of $\mathrm{CO}_{2}$ is occurring [Tans et al., 1990]. The gradient in atmospheric $\mathrm{CO}_{2}$ obtained in this model run may also indicate a somewhat larger terrestrial sink in the Northern Hemisphere than previously considered [Tans et al., 1990].

\subsection{Three-dimensional $\mathrm{CO}+\mathrm{OH}$ Reaction Influence on the Global Budget of Atmospheric $\mathrm{CO}_{2}$}

The main sources/sinks of the global atmospheric $\mathrm{CO}_{2}$ budget are related to surface sources and sinks, mainly fossil fuel, biomass burning, and exchange with the ocean and the terrestrial biosphere. However, the occurrence and oxidation of $\mathrm{CO}$ in the atmosphere may also create $\mathrm{CO}_{2}$ throughout the volume of the atmosphere [Enting and Mansbridge, 1991]. The reaction

$$
\mathrm{CO}+\mathrm{OH} \rightarrow \mathrm{CO}_{2}+\mathrm{H}
$$

has been evaluated in the NCAR CCM2 based chemical transport model (CTM). The model has $\mathrm{CO}$ sources from fossil fuel burning, biomass burning, and the oxidation of methane and nonmethane hydrocarbons. These sources integrate globally to $1650 \mathrm{Tg} \mathrm{CO}$ per year. We have examined the seasonal variation in the global three-dimensional distribution of $\mathrm{CO}_{2}$ produced from the oxidation of $\mathrm{CO}$. We find $0.7 \mathrm{GtC}$ (as $\mathrm{CO}_{2}$ ) in close agreement with the calculation of Enting and Mansbridge [1987]. This gives us confidence that the $\mathrm{CTM} \mathrm{OH}$ fields and $\mathrm{CO}_{2}$ production rates are reasonable. Plate la shows the vertically integrated $\mathrm{CO}_{2}$ production in moles $\mathrm{m}^{-2} \mathrm{yr}^{-1}$ for the month of January.

The January atmospheric $\mathrm{CO}_{2}$ production (Plate 1a) is largest in the atmosphere where there are substantial fluxes of $\mathrm{CO}$ from biomass burning concurrent with relatively high atmospheric $\mathrm{OH}$ concentrations. In contrast, the July simulations (Plate 1b) show the largest $\mathrm{CO}_{2}$ production over industrialized regions of the northern hemisphere. This is due to the $\mathrm{OH}$ concentration being higher over the industrial fossil fuel related surface emissions during this time of year. In January, $\mathrm{OH}$ is low over the winter northern hemisphere and high over areas close to biomass burning related surface emissions. Figures $16 \mathrm{a}$ and $16 \mathrm{~b}$ show the vertically integrated production of $\mathrm{CO}_{2}$ as a function of latitude. In January Figure $16 \mathrm{a}$, the largest $\mathrm{CO}_{2}$ production occurs between $40^{\circ} \mathrm{N}$ and $60^{\circ} \mathrm{S}$ with maxima from the equator to $10^{\circ}$ $\mathrm{N}$ and $\sim 30^{\circ} \mathrm{S}$. This is a result of the tropical areas of biomass burning coinciding in space with regions of elevated $\mathrm{OH}$ concentration. In Figure $16 \mathrm{~b}$ the calculation for July, the 

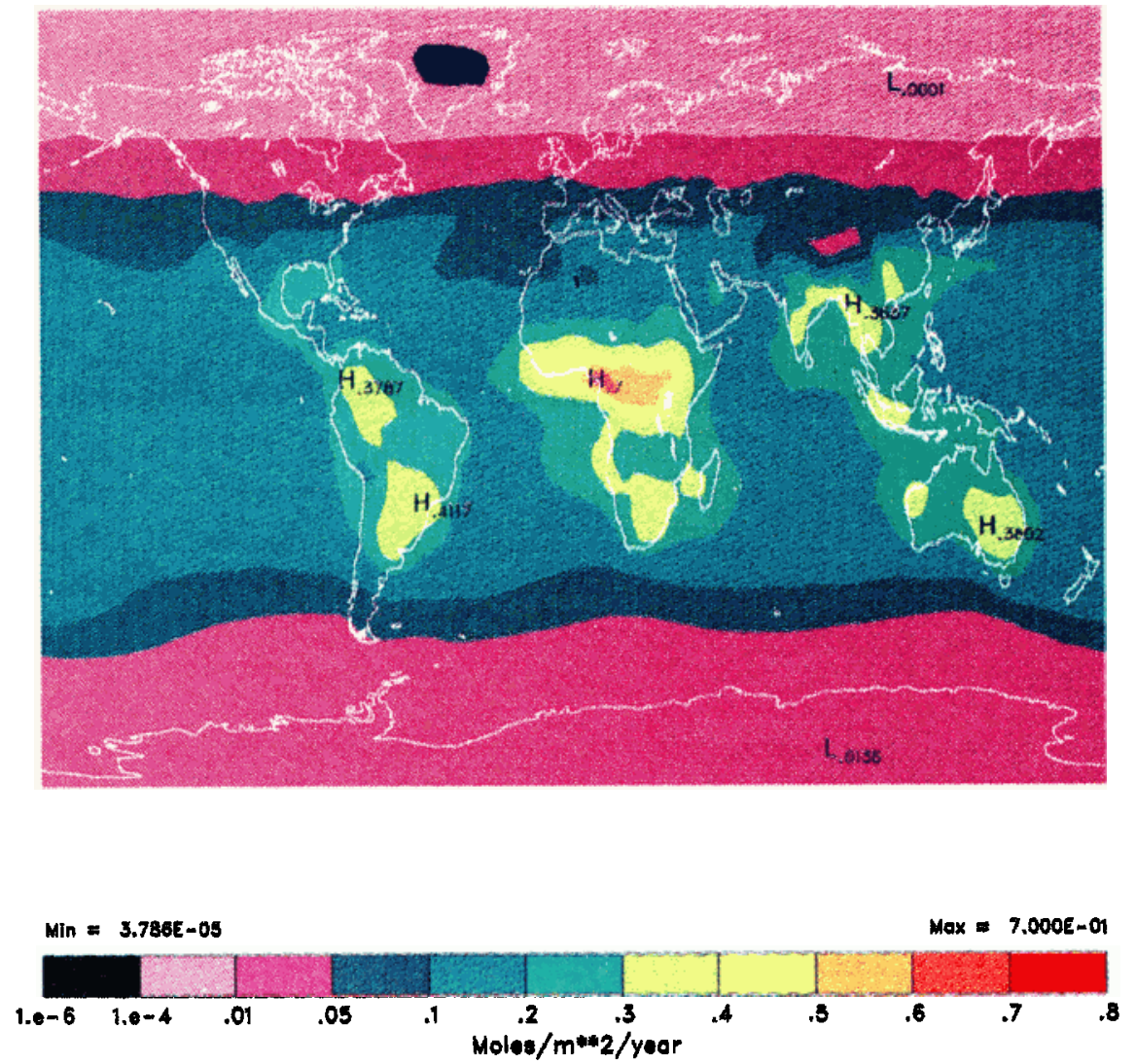

Plate 1a. The vertically intergrated production of atmospheric $\mathrm{CO}_{2}$ from the $\mathrm{CO}+\mathrm{OH}$ reaction as computed for January.
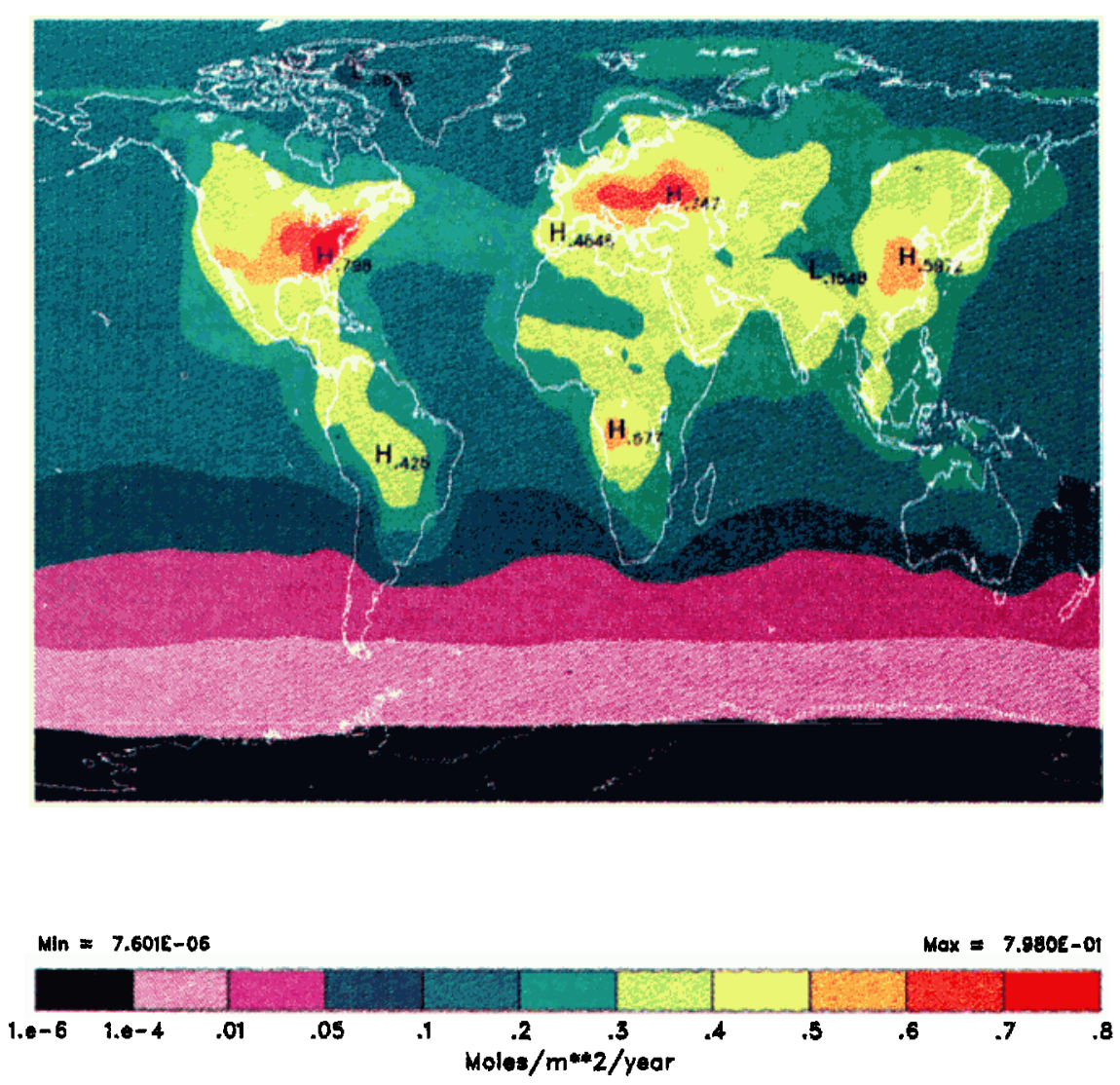

Plate 1b. The vertically intergrated production of atmospheric $\mathrm{CO}_{2}$ from the $\mathrm{CO}+\mathrm{OH}$ reaction as computed for July. 


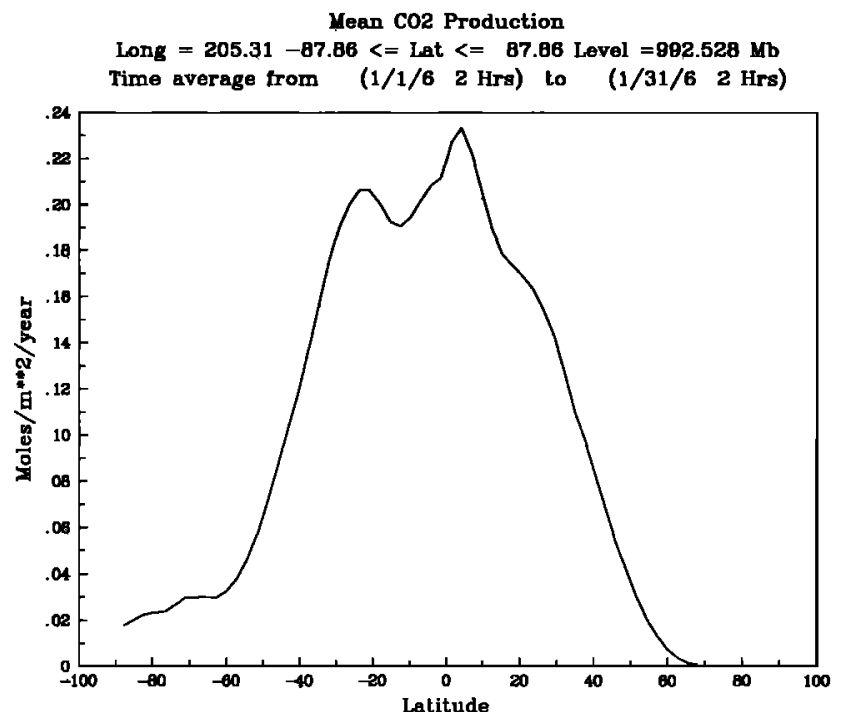

Figure 16a. The zonal average of the vertically intergrated $\mathrm{CO}_{2}$ production from the $\mathrm{CO}+\mathrm{OH}$ reaction as computed for January.

region of maximum $\mathrm{CO}_{2}$ production from the oxidation of $\mathrm{CO}$ is over the industrialized areas of the northern hemisphere. This anthropogenic $\mathrm{CO}$ is most prevalent over continental regions and $\mathrm{OH}$ is much higher at these latitudes during the boreal summer than in the January run.

The vertical distribution of the $\mathrm{CO}+\mathrm{OH}$ reaction for each of the two months discussed is very similar, but there are subtle differences. Since $\mathrm{OH}$ is a product of $\mathrm{O}\left({ }^{1} D\right)$ and $\mathrm{H}_{2} \mathrm{O}(\mathrm{g})$ (water vapor), most of the production occurs in the lower troposphere where $\mathrm{H}_{2} \mathrm{O}(\mathrm{g})$ concentrations are higher. The biomass burning areas are closer to major convective centers than other surface $\mathrm{CO}$ sources. This may allow for more $\mathrm{CO}$ and $\mathrm{H}_{2} \mathrm{O}$ (and by implication $\mathrm{OH}$ ) to reach greater altitudes on a regional basis. Care must be applied in using such data in inverse approaches whereby atmospheric transport statistics are coupled with multistation time series observations of atmospheric $\mathrm{CO}_{2}$ concentration.

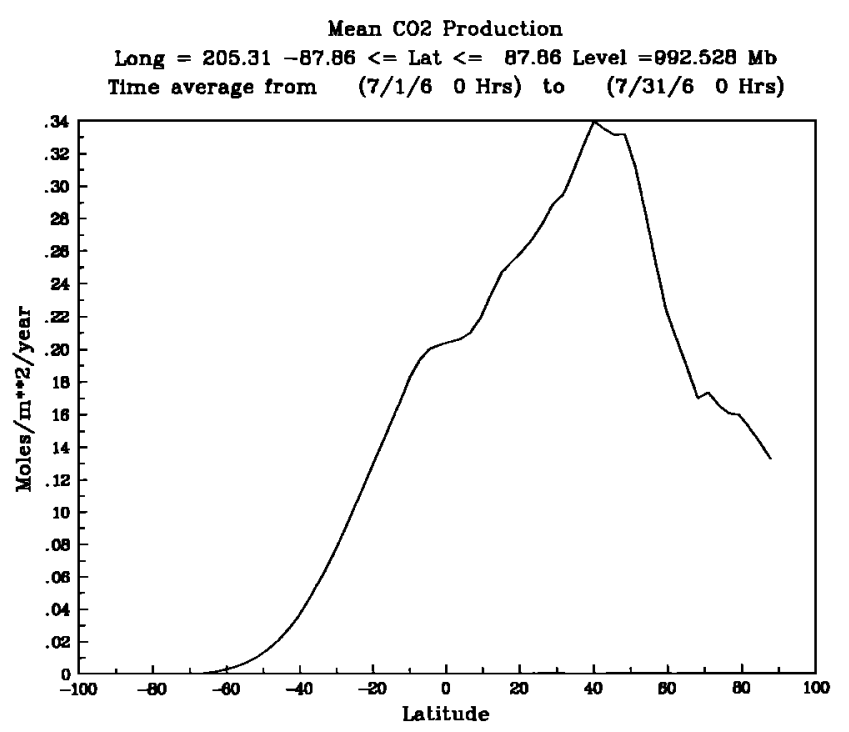

Figure 16b. The zonal average of the vertically intergrated $\mathrm{CO}_{2}$ production from the $\mathrm{CO}+\mathrm{OH}$ reaction as computed for July.

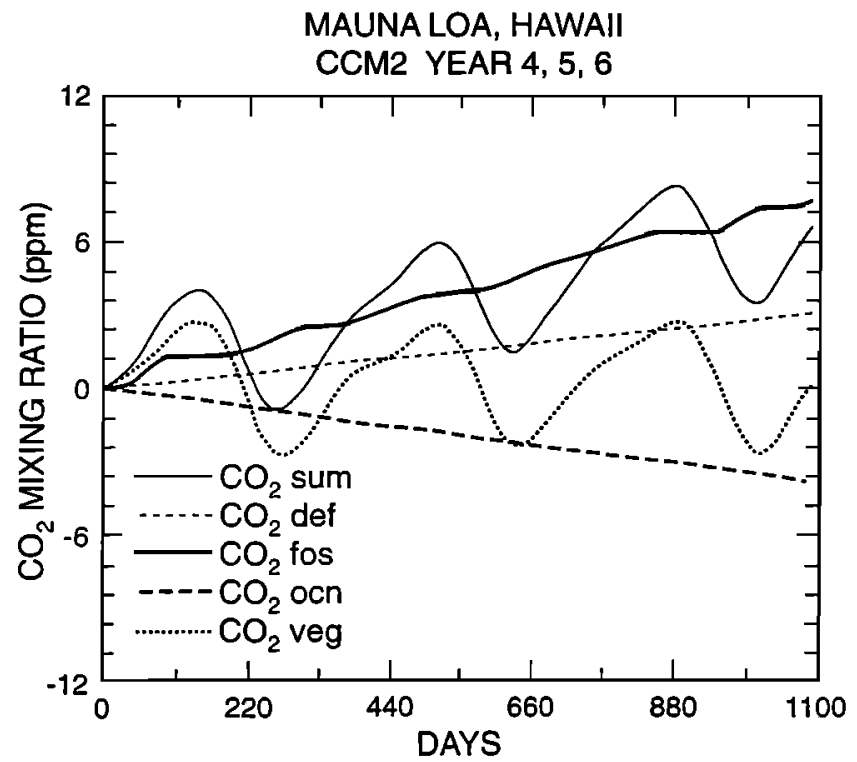

Figure 17. The smoothed time series of the total $\mathrm{CO}_{2}$ tracer $\left(\mathrm{CO}_{2}\right.$ sum) and the component tracers that make up the 'total' or 'sum' tracer signal at Mauna Loa for year 4, 5, and 6 of the model run. Clearly, the seasonality of the total tracer is heavily influenced by the seasonality of the vegetative tracer.

\section{Discussion}

The NCAR CCM2 has been adapted for use in studying the global $\mathrm{CO}_{2}$ cycle. At Mauna Loa, Hawaii, the model produces seasonal variability that is quite close to the NOAA/CMDL observations. The seasonal cycle is within $10 \%$ of observations for many sites in the northern hemisphere. This is directly related to the climatology of the parameterization of the $\mathrm{CO}_{2}$ exchanges with the terrestrial biosphere developed by Fung et al. (1987).

The numerical experiments were formulated in such a way so as to allow the quantitative apportionment of the different

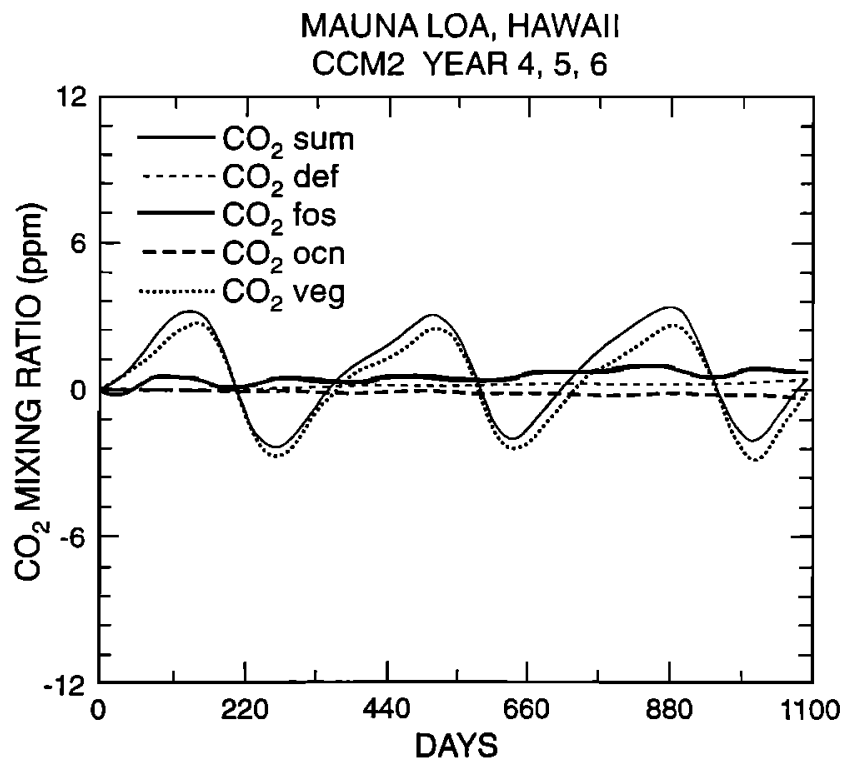

Figure 18. The time series of all the $\mathrm{CO}_{2}$ tracers, smoothed and detrended, at Mauna Loa, Hawaii, for three model years. 
BERMUDA CCM2 YEAR 4, 5, 6

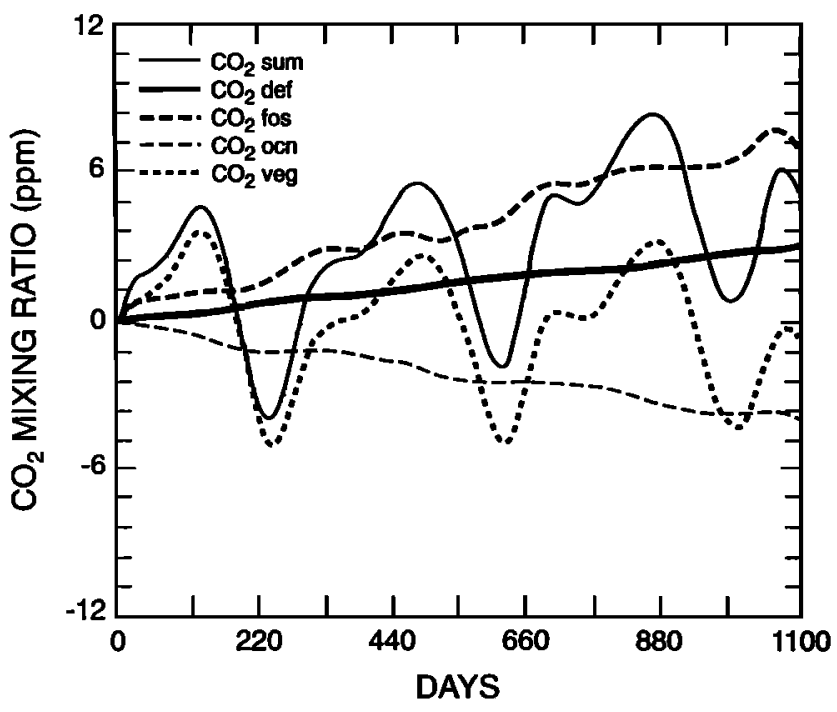

Figure 19. The time series of all the $\mathrm{CO}_{2}$ tracers, smoothed, at Bermuda for 3 model years.

sources to the overall predicted $\mathrm{CO}_{2}$ concentration. For example, Figure 17 shows the contribution of the four different source components to the total $\mathrm{CO}_{2}$ tracer $\left(\mathrm{CO}_{2}\right.$ sum $)$ at Mauna Loa, Hawaii, for years 4,5 , and 6 of the model run. The direct response of the total $\mathrm{CO}_{2}$ tracer $\left(\mathrm{CO}_{2} \mathrm{sum}\right)$ to the variations in terrestrial biosphere tracer $\left(\mathrm{CO}_{2} \mathrm{veg}\right)$ is clear. However, some of the details of the correlated variability are not directly related to the terrestrial biosphere alone and some of the variability is due to variability in the transport of the fossil fuel tracer $\left(\mathrm{CO}_{2}\right.$ fos $)$. Note that since the ocean $\left(\mathrm{CO}_{2} \mathrm{ocn}\right)$ is a net sink in our model, the tracer decreases in concentration over the 3-year model run period. Both the fossil fuel and the deforestation/land use change $\left(\mathrm{CO}_{2} \mathrm{def}\right)$ are net sources to the atmospheric flow and increase in time. Figure 18 shows the detrended ensemble of different tracers making up the seasonal

\section{BERMUDA CCM2 YEAR 4, 5, 6}

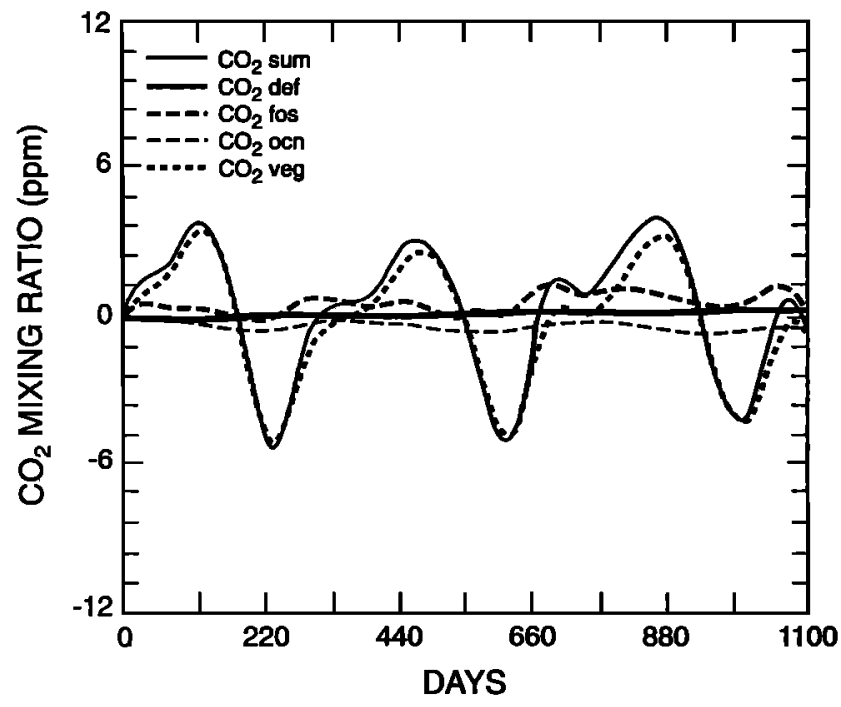

Figure 20. The smoothed, detrended time series of all atmospheric $\mathrm{CO}_{2}$ tracers at Bermuda for 3 model years.

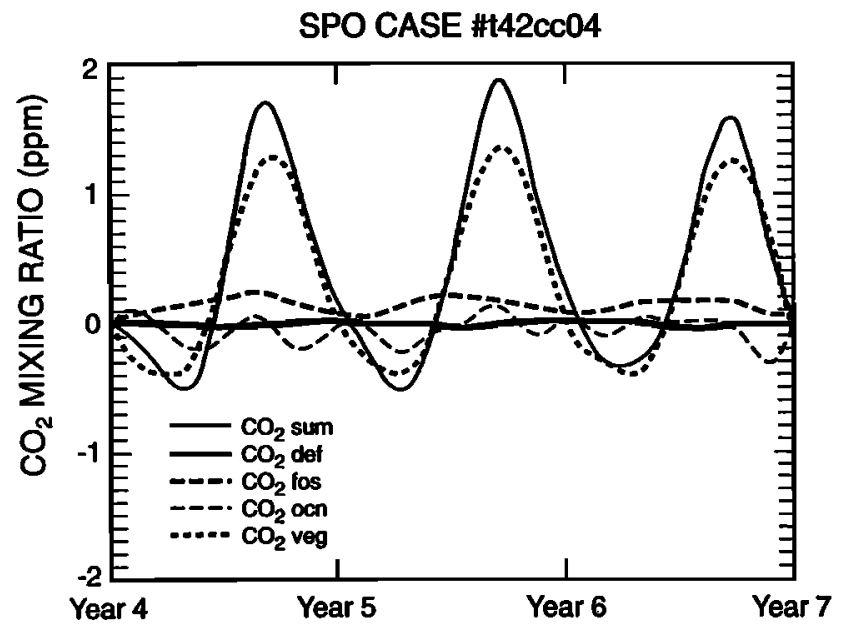

Figure 21. The smoothed, detrended time series of all atmospheric $\mathrm{CO}_{2}$ tracers at the south pole for three model years.

cycle at Mauna Loa. Again, it is obvious that most of the variability in the total $\mathrm{CO}_{2}$ tracer $\left(\mathrm{CO}_{2} \mathrm{sum}\right)$ is due to the terrestrial biosphere $\left(\mathrm{CO}_{2} \mathrm{veg}\right)$ with a small portion of the variability due to the variability in the transport of the fossil fuel $\left(\mathrm{CO}_{2}\right.$ fos) tracer from continental regions.

Figure 19 shows the contribution of the four different source components to the total $\mathrm{CO}_{2}$ tracer $\left(\mathrm{CO}_{2}\right.$ sum) at Bermuda for years 4, 5, and 6 of the model run. As in Figure 18 , the majority of the variability in the total $\mathrm{CO}_{2}$ tracer is due to the terrestrial biosphere. As seen in the detrended calculations (Figure 20) the 'bump' in the winter-spring months is related mainly to the vegetative tracer, but a small enhancement is provided by the increased frequency of advection of polluted, $\mathrm{CO}_{2}$ rich air from northern midlatitude continental regions.

As discussed in a previous section, the simulated amplitude of the seasonal cycle of atmospheric $\mathrm{CO}_{2}$ at the South Pole is roughly $100 \%$ greater than in the observations. To more closely examine the possible reasons behind this we again look at the contribution of the four different source components to the total $\mathrm{CO}_{2}$ tracer $\left(\mathrm{CO}_{2}\right.$ sum), Figure 21 . The terrestrial biosphere tracer $\left(\mathrm{CO}_{2} \mathrm{veg}\right)$ is clearly contributing the largest part of the $\sim 2.2 \mathrm{ppm}$ seasonal cycle. The seasonality of the interhemispheric transport of northern hemisphere air to the south pole is evidenced by the variation in the fossil fuel tracer. There are at least two plausible explanations for the enhanced seasonal cycle amplitude at the south pole in the model. One is that the interhemispheric transport is larger than in the real world; however, this would serve to decrease the interhemispheric gradient, which as noted in a previous section, is already too large compared to observations. This suggests that gross errors in the interhemispheric transport is not that plausible. The other explanation is that the ocean sink during austral springsummer is not strong enough in the annual mean treatment used here [e.g. Pearman and Hyson, 1986]. That is, if the seasonality of air-sea exchange is important to the interpretation of the south pole atmospheric $\mathrm{CO}_{2}$ observational record, then the transport in the CCM2 may be adequate and improvements in the ocean treatment may be required. 


\section{Januray $\mathrm{CO}_{2}$ Flux For the Ocean}

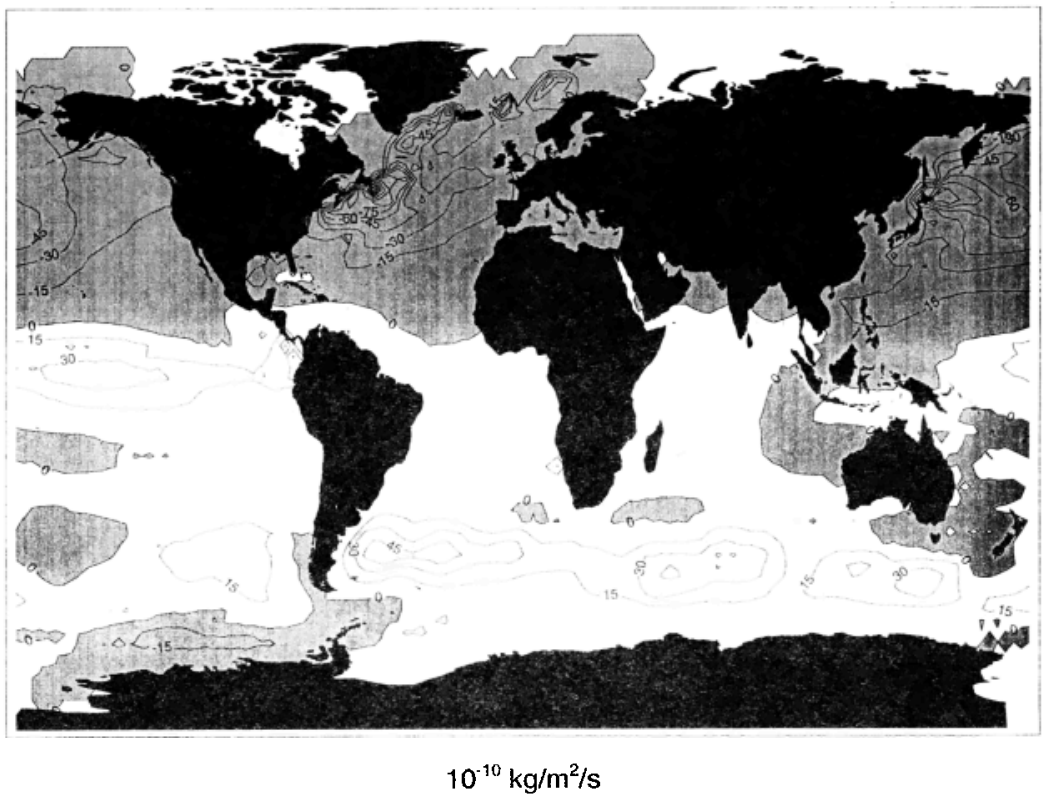

Figure 22a. The global air-sea exchange of $\mathrm{CO}_{2}$ as computed for January using the surface ocean $p \mathrm{CO}_{2}$ estimated by the Max-Planck Institute (MPI-H) ocean general circulation model and a ${ }^{14} \mathrm{C}$ consistent transfer velocity.

To test this possibility, we used an alternative ocean forcing provided by the MPI-H ocean general circulation model. This model provided the monthly varying estimates of $p \mathrm{CO}_{2}$ which we coupled with the exchange coefficients of Erickson [1993] to estimate the flux. Figures $22 \mathrm{a}$ and $22 \mathrm{~b}$ show the MPI-H ocean model based $\mathrm{CO}_{2}$ fluxes for January and July, respectively. Note the strong seasonalıty at middlehigh latitudes of both hemispheres. Figure 23 shows the differences between the two runs of the atmospheric transport model using the two different treatments of the air-sea $\mathrm{CO}_{2}$ flux for three stations in middle to high-latitude southern hemisphere. The monthly varying $p \mathrm{CO}_{2}$ treatment clearly serves to attenuate the amplitude of the seasonal cycle at the three southern hemisphere stations. With the MPI ocean the amplitudes are roughly halved, bringing them into much better agreement with the observational record; the model amplitudes shown in Figure 3 are brought much closer to the observations for those stations south of $30^{\circ} \mathrm{S}$.

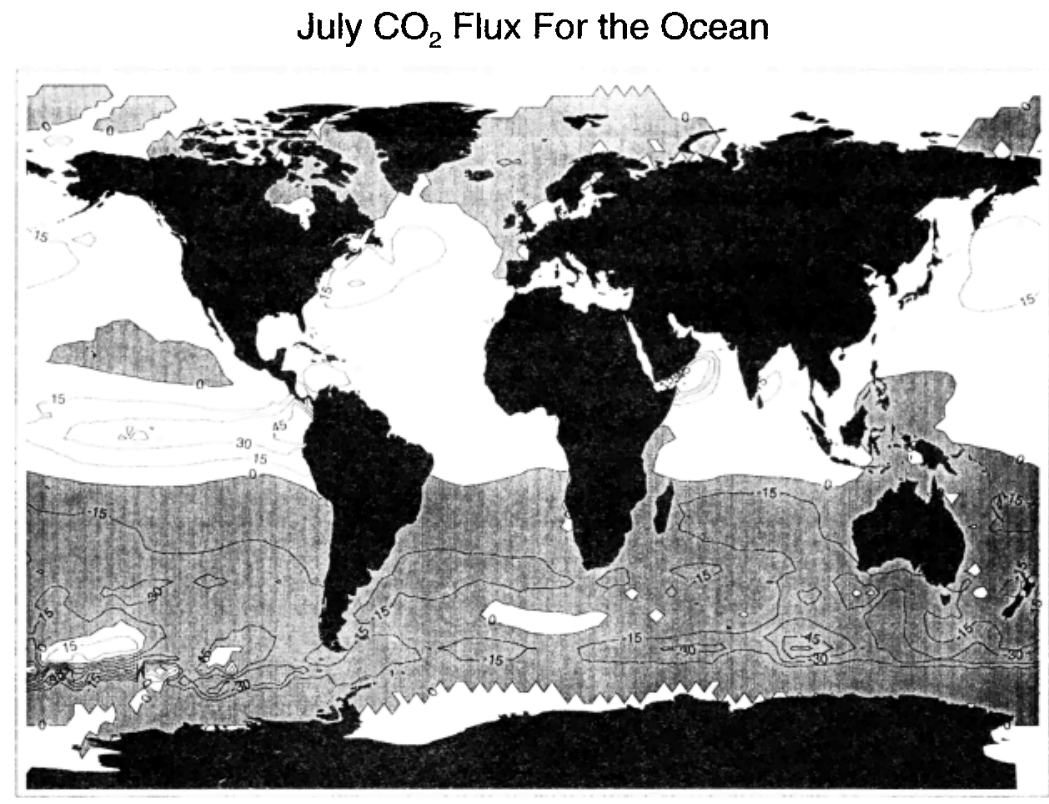

$10^{-10} \mathrm{~kg} / \mathrm{m}^{2} / \mathrm{s}$

Figure 22b. The global air-sea exchange of $\mathrm{CO}_{2}$ as computed for July using the surface ocean $p \mathrm{CO}_{2}$ estimated by the MPI-H ocean general circulation model and a ${ }^{14} \mathrm{C}$ consistent transfer velocity. 
AMSTERDAM ISLAND - $38^{\circ} \mathrm{S}, 77^{\circ} \mathrm{E}$
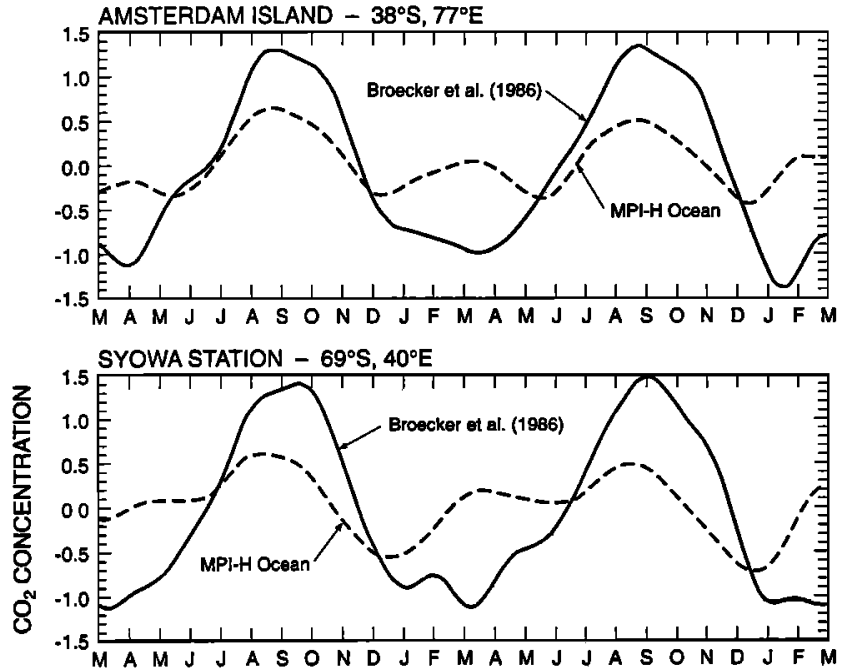

SOUTH POLE $-90^{\circ} \mathrm{S}, 25^{\circ} \mathrm{W}$

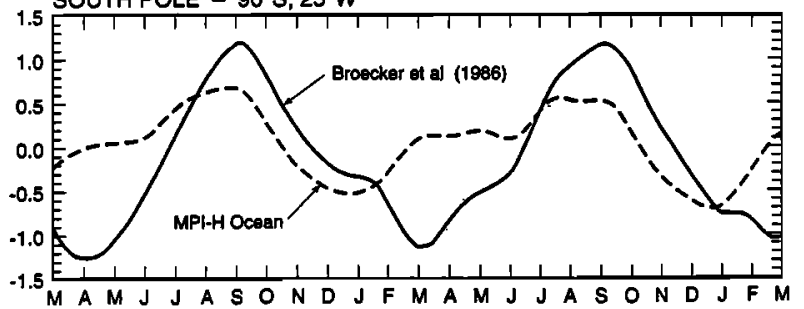

Figure 23. The comparison at three middle to high-latitude southern hemisphere sites of the atmospheric $\mathrm{CO}_{2}$ concentration for 2 years using the two different treatments of the air-sea exchnage of $\mathrm{CO}_{2}$. Note that the ocean treatment with the monthly variability serves to attenuate the amplitude of the seasonal cycle by some $50 \%$ as compared to the annual mean ocean forcing. This brings the carbon cycle model into much better agreement with the observational record for these southern hemisphere regions.

The observed seasonal cycle of atmospheric $\mathrm{CO}_{2}$ concentration at a particular site is a strong function of exposure to air that has been in contact with the terrestrial biosphere. As a case study of a particular aspect of the model performance, we have examined the frequency and magnitude of $\mathrm{CO}_{2}$-depleted air parcels advecting off the North American continent during the times of the year when the terrestrial biosphere is actively removing $\mathrm{CO}_{2}$ from the atmosphere. The model predictions and observational data both reflect the infrequent rapid advection of air parcels from the North American continent to Bermuda under specific meteorological conditions, a feature that monthly mean wind fields can not yield. We feel that it is quite encouraging to see that such details of the carbon model are realistic as well as the largescale constraints such as magnitude of the seasonal cycle at specific observational stations.

The interhemispheric gradient of atmospheric $\mathrm{CO}_{2}$ concentrations is roughly $4 \mathrm{ppm}$ too high in the model run compared to observation, consistent with previous studies [Keeling et al., 1989a, b; Tans et al., 1990]. An enhancement in a northern hemisphere sink appears to be lacking in the model source/sink formulations. An interesting trapping of the terrestrial biosphere tracer occurs in the northern hemisphere that has the effect of increasing the interhemispheric gradient (Figure 15). A test of the model vertical mixing behavior is the phase and amplitude of the seasonal cycle as a function of elevation. The model and data from the Hawaii stations located at 3 and $3400 \mathrm{~m}$ amsl both indicate an attenuation of the seasonal cycle in atmospheric $\mathrm{CO}_{2}$ as one moves higher in the atmosphere. This same general trend is also observed at Sendai, Japan. However, as discussed in section 4.2.3, at Cape Grim, Tasmania, the amplitude of the seasonal cycle actually increases by $\sim 20 \%$ with altitude due to the forcing largely originating in the northern hemisphere.

Various different terrestrial biosphere 'source-sink' parameterizations are being prepared for use in further model development on a range of spatial and temporal scales. Here, we examine the model output using two different treatments of the terrestrial biosphere that have no net uptake of $\mathrm{CO}_{2}$ in an annual cycle. Figures $24 a$ and $24 b$ show the computed seasonal cycle for Alert, Northwest Territories, Canada, using the terrestrial biosphere exchange parameterizations of Fung et al., [1987] and Friedlingstein et al., [1992]. Note that the Fung et al. [1987] parameterization yields reasonable results for the several remote, oceanic stations discussed in previous sections. Figure $24 \mathrm{a}$ shows the detrended $\mathrm{CO}_{2}$ concentration for two seasonal cycles at Alert and 1 and 2 grid points north of Alert as compared to the flask data using the terrestrial biosphere parameterization of Fung et al. (1987]. Clearly, the Fung et al. [1987] treatment results in an atmospheric $\mathrm{CO}_{2}$ concentration that precedes the observed the $\mathrm{CO}_{2}$ 'drawdown' by a few months. This results in the overestimation of the $\mathrm{CO}_{2}$ concentration from May to August. The amplitude of the seasonal cycle is reasonably well modeled. To assess the possible usefulness of an alternative treatment of terrestrial biosphere-atmosphere $\mathrm{CO}_{2}$ exchange, we have used the terrestrial biosphere flux model of Friedlingstein et al. [1992] during the exact same model run. Figure $24 \mathrm{~b}$ shows the same quantities as Figure 24a, except the CCM2 run with the Friedlingstein et al. [1992] flux model

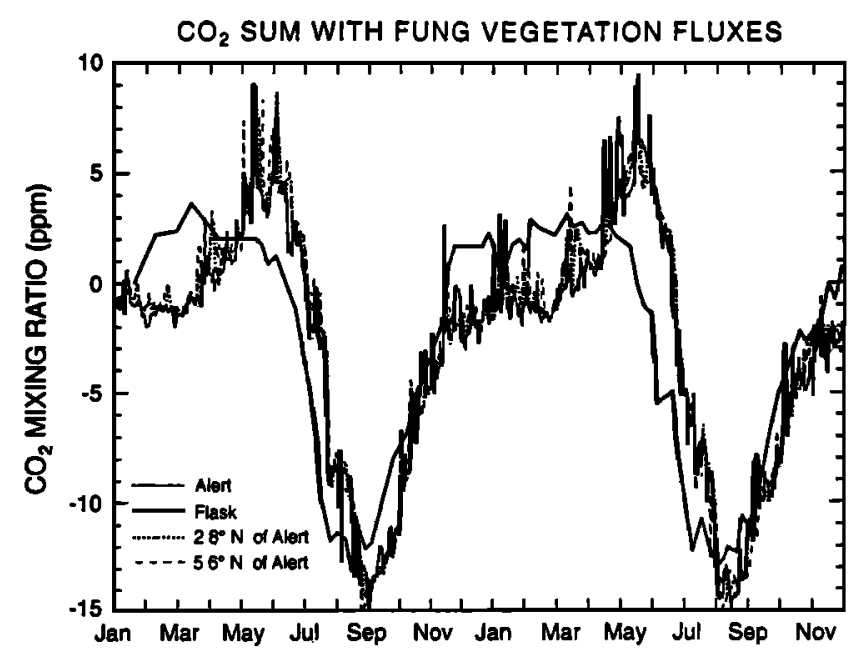

Figure 24a. The detrended seasonal cycle of the modeled atmospheric $\mathrm{CO}_{2}$ concentration at and around Alert, Northwest Territories, Canada, for two seasonal cycles using the terrestrial biosphere treatment of Fung et al. [1987]. For comparison the thick solid line is the observational flask data of the NOAA/CMDL group. 


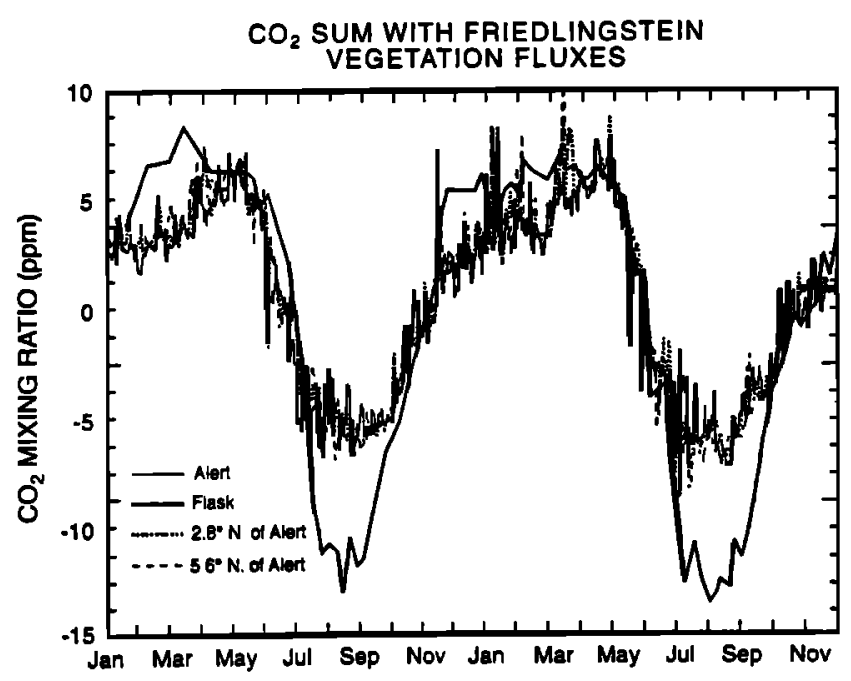

Figure 24b. The detrended seasonal cycle of the modeled atmospheric $\mathrm{CO}_{2}$ concentration at and around Alert, Northwest Territories, Canada, for two seasonal cycles using the terrestrial biosphere treatment of Friedlingstein et al. [1992]. For comparison, the thick solid line is the observational flask data of the NOAA/CMDL group.

output is plotted. Note that the $\mathrm{CO}_{2}$ 'drawdown' is timed more realistically than the Fung et al. [1987] approach; however, the amplitude of the seasonal cycle is too small. The creation, testing, and use of various surface source/sink models of $\mathrm{CO}_{2}$ exchange with the terrestrial biosphere is an area of active research. Future simulations of the seasonal cycle of terrestrial biosphere-atmosphere exchange of $\mathrm{CO}_{2}$ will attempt to glean the best features of a variety of different treatments.

\section{Conclusions and Future Directions}

A new three-dimensional global atmospheric chemistry transport model, the NCAR CCM2, has been adapted for use in studying the global $\mathrm{CO}_{2}$ cycle. We present calculations of atmospheric $\mathrm{CO}_{2}$ temporal and spatial distributions. We use surface source terms that include fossil fuel, land use change, oceanic exchange, and monthly resolved vegetative fluxes. The amplitude of the seasonal cycle is reasonably well modeled in the remote oceanic northern hemisphere, however, there are disagreements between the model and the data in the southern hemisphere when using an annual mean ocean chemical forcing. The amplitude of the seasonal cycle at the south pole is brought down into better agreement with observational data using the monthly varying MPI-H OGCM generated estimates of surface ocean $p \mathrm{CO}_{2}$.

The low-frequency variability of the model is found to agree quite well with the observed low-frequency variability of the NOAA/CMDL observational data. The model appears to be able to replicate the infrequent but observed minima in atmospheric $\mathrm{CO}_{2}$ concentrations that occur a few times a summer at Bermuda. The model allows these unique and infrequent features of the Earth $\mathrm{CO}_{2}$ system to be captured. Vertical phasing and amplitude of seasonal cycle in both model and data agree reasonably well at the two Hawaii stations, Cape Kumakahi and Mauna Loa, as well as under the unique circulation patterns of the midlatitude southern hemisphere (Cape Grim, Tasmania). The increase in seasonal amplitude of atmospheric $\mathrm{CO}_{2}$ with altitude at Cape Grim in the data as well as the model simulations leads us to conclude that the vertical structure of interhemispheric transport is reasonably well simulated by the CCM2.

The global tropospheric production of $\mathrm{CO}_{2}$ from the $\mathrm{CO}+$ $\mathrm{OH}$ reaction is estimated at $0.7 \mathrm{Gt} \mathrm{C}$ (as $\mathrm{CO}_{2}$ ) per year using a chemical transport model. There are large three-dimensional spatial and temporal variations in the production of $\mathrm{CO}_{2}$ in the troposphere. In January the largest $\mathrm{CO}_{2}$ production occurs between $40^{\circ} \mathrm{N}$ and $60^{\circ} \mathrm{S}$ with maxima from the equator to $10^{\circ}$ $\mathrm{N}$ and $\sim 30^{\circ} \mathrm{S}$. This is a result of the tropical areas of biomass burning coinciding in space with regions of elevated $\mathrm{OH}$ concentration. The calculation for July indicates that the region of maximum $\mathrm{CO}_{2}$ production from the oxidation of $\mathrm{CO}$ is over the industrialized areas of the northern hemisphere. This anthropogenic $\mathrm{CO}$ is most prevalent over continental regions and $\mathrm{OH}$ is higher at these latitudes during the boreal summer than in the January run. These production terms may be a consideration in various inversion techniques designed to elucidate surface-based sources and sinks.

We find that for observational stations quite close to areas of active terrestrial biosphere-atmosphere exchange, such as Alert, Northwest Territories, Canada, the two terrestrial biosphere flux models we used have significant differences as compared to each other and observational data. This aspect of the terrestrial flux models will be examined in detail in later model development actvities.

There are several deficiencies in the model results that will guide further research. The residuals of the modeled atmospheric $\mathrm{CO}_{2}$ concentrations have a seasonality that does not consistently occur in the observed data. We will assess individual events that have significant impact on the modelcomputed residuals on synoptic timescales. The treatment of the ocean $\mathrm{CO}_{2}$ fluxes will be improved via the increasing database of surface ocean $p \mathrm{CO}_{2}$ content as well as various ocean model predictions. In these initial validation experiments, we have used boundary forcings that, in total, result in the accumulation of $\mathrm{CO}_{2}$ in the model atmosphere that is larger than in the observational record. In the future, we will use a variety of 'fertilization' models of the terrestrial biosphere to asses the impact of such processes on the computed interhemispheric gradient as well as the $\mathrm{CO}_{2}$ accumulation rate in the atmosphere. In addition, we will explore the possible role of the ocean in the enhanced uptake of $\mathrm{CO}_{2}$ over the last century or so.

A clear, well-defined future direction that this CCM2based $\mathrm{CO}_{2}$ cycle model will follow is the inclusion of the stable and unstable isotopes of carbon and the stable isotopes of oxygen in the simulations; ${ }^{14} \mathrm{CO}_{2},{ }^{13} \mathrm{CO}_{2}$ and $\mathrm{C}^{18} \mathrm{O}^{16} \mathrm{O}$ provide unique and powerful tools by which the validity of various $\mathrm{CO}_{2}$ source/sink estimates at the Earth surface may be tested. The detailed treatment of these isotopic tracers will inevitably result in a much more complex modeling effort related to the terrestrial and marine biosphere, both components of the Earth scale $\mathrm{CO}_{2}$ system that ultimately strongly influence our planet's climate.

Acknowledgments. We acknowledge stimulating discussions with I. Fung, C. D. Keeling and S. Piper. This is a contribution of the Global Carbon Cycle Model (GCCM) project as part of the Climate Modeling, Analysis, and Prediction (CMAP) program and CSM. Additional support 
is acknowledged from the GESMP program. NCAR is supported by the National Science Foundation.

\section{References}

Bolin, B., On the exchange of carbon dioxide between the atmosphere and the sea, Tellus, 12, 274-281, 1960.

Boville, B. A., H. R. Holton, and P. W. Mote, Simulation of the Pinatubo aerosol cloud in general circulation model, Geophys. Res. Lett., 18, 2281-2284, 1992.

Briegleb, B. P., Delta-Eddington approximation for solar radiation in the NCAR community climate model. J. Geophys. Res., 97, 7603-7612, 1992.

Broecker, W. S., T. Takahashi, H. J. Simpson, and T. H. Peng, Fate of fossil fuel carbon dioxide and the global carbon budget, Science, 206, 409-418, 1979.

Broecker, W. S., J. R. Ledwell, T. Takahashi, R. Weiss, L. Merlivat, L. Memery, T.-H. Peng, B. Jahne, and K. O. Munnich, Isotopic versus micrometeorological ocean $\mathrm{CO}_{2}$ fluxes: A serious conflict, $J$. Geophys. Res., 91, 10,517-10,528, 1986.

Conway, T. J., P. P. Tans, L. S. Waterman, K. W. Thoning, K. A. Masarie, and R. H. Gammon, Atmospheric carbon dioxide measurements in the remote global troposphere, 1981-1984, Tellus, $40 B, 81-115,1988$

Denning, A. S., Investigations of the transport, sources and sinks of atmospheric $\mathrm{CO}_{2}$ using a general circulation model, Atmos. Sci. Pap. 564, 336 pp., Colo. State Univ., Fort Collins, 1994.

Denning, A. S., I. Y. Fung, and D. A. Randall, Latitudinal gradient of atmospheric $\mathrm{CO}_{2}$ due to seasonal exchange with land biota, Nature, $376,240-243,1995$.

Enting, I. G. and J. V. Mansbridge, The incompatibility of ice-core $\mathrm{CO}_{2}$ data with reconstructions of biotic $\mathrm{CO} 2$ sources, Tellus, 39, 318-325, 1987.

Enting, I. G.. and J. V. Mansbridge, Latitudinal distribution of sources and sinks of $\mathrm{CO}_{2}$ : Results of an inversion study, Tellus, 43, 156-170, 1991.

Erickson, D. J., III, A stability dependent theory for air-sea gas exchange, J. Geophys. Res., 98, 8471-8488, 1993.

Etcheto, J., and L. Merlivat, Satellite determination of the carbon dioxide exchange coefficient at the ocean-atmosphere interface: A first step, J. Geophys. Res., 93, 15,669-15,678, 1988.

Friedlingstein, P., C. Delire, J.-F. Muller, and J. C. Gerard, The climate induced variation of the continental biosphere: A model simulation of the last glacial maximum, Geophys. Res. Lett.,19, 897-900, 1992.

Fung, I., K. Prentice, E. Matthews, J. Lemer, and G. Russell, Threedimensional tracer model study of atmospheric $\mathrm{CO}_{2}$ : Response to seasonal exchanges with the terrestrial biosphere, $J$. Geophys. Res. $88,1281-1294,1983$.

Fung, I., C. Tucker, and K. Prentice, Application of AVHRR vegetation index to study atmosphere-biosphere exchange of $\mathrm{CO}_{2}, J$. Geophys. Res., 92, 2999-3016, 1987.

Gillette, D. A., W. D. Komhyr, L. S. Waterman, L. P. Steele, and R. H. Gammon, The NOAA/GMCC continuous $\mathrm{CO}_{2}$ record at the south pole, J. Geophys. Res., 92, 4231-44240, 1987.

Hack, J. J., Parameterization of moist convection in the NCAR Community Climate Model (CCM2), J. Geophys. Res.3, 5541, 1994.

Hack, J. J., B. A. Boville, J. T. Kiehl, P. J. Rasch, and D. L. Williamson, Climate statistics from the National Center for Atmospheric Research community climate model, CCM2, J. Geophys. Res., 99, 20,785$20,814,1994$.

Harris, J. M., and J. D. Kahl, A descriptive atmospheric transport climatology for the Mauna Loa Observatory using clustered trajectories, J. Geophys. Res., 95, 13,651-13,667, 1990.

Harris, J. M., P. P. Tans, E. J. Dlugokencky, K. A. Masarie, P. M. Lang, S. Whittlestone, and L. P. Steele, Variations in atmospheric methane at Mauna Loa Observatory related to long-range transport, $J$. Geophys. Res., 97, 6003-6010, 1992.

Hartley, D., D. L. Williamson, P. J. Rasch, and R. Prinn, Examination of tracer transport in the NCAR CCM2 by comparison of CFCl simulations with ALE/GAGE observations, J. Geophys. Res., 6 , $12,885,1994$

Heimann, M., and C. D. Keeling, A three-dimensional model of atmospheric $\mathrm{CO}_{2}$ transport based on observed winds, 2, Model description and simulated tracer experiments, in Aspects of Climate
Variability in the Pacific and the Western Americas, edited by D. H. Peterson, AGU, Washington, D. C., 1989.

Heimann, M., C. D. Keeling, and C. J. Tucker, A three-dimensional model of atmospheric $\mathrm{CO}_{2}$ transport based on observed winds, 3, Seasonal cycle and synoptic timescale variations, in Aspects of Climate Variability in the Pacific and the Western Americas, edited by D. H. Peterson, AGU, Washington, D. C., 1989.

Holtslag, A. A. M., and B. A. Boville, Local versus nonlocal boundarylayer diffusion in a global climate model. J. Climate, In press, 1993.

Holtslag, A. A. M., E. I. F. de Bruijn and H.-L. Pan, A high resolution air mass transformation model for short-range weather forecasting, Mon. Weather Rev., 118, 1561-1575, 1990.

Houghton, R. A., The global carbon cycle, Science, 241, 1736, 1988.

Keeling, C. D., A. F. Carte,r and W. G. Mook, Seasonal, latitudinal and secular variations in the abundance and isotopic ratios of atmospheric $\mathrm{CO}_{2}$, J. Geophys. Res., 89, 4615-4628, 1984.

Keeling, C. D., R. B. Bacastow, A. E. Bainbridge, C. A. Ekdahl, P. R. Guenther, L. S. Waterman, and J. F. S. Chin, Atmospheric carbon dioxide variations at Mauna Loa Observatory, Hawaii, Tellus, 28, 538-551, 1976.

Keeling, C. D., R. B. Bacastow, A. F. Carter, S. C. Piper, T. P. Whorf, M. Heimann, W. G. Mook, and H. Roeloffzen, A three-dimensional model of atmospheric $\mathrm{CO}_{2}$ transport based on observed winds, 1 . Analysis of observational data, in Aspects of Climate Variability in the Pacific and the Western Americas, edited by D. H. Peterson, AGU, Washington, D. C., 1989a.

Keeling, C. D., S. C. Piper, and M. Heimann, A three-dimensional model of atmospheric $\mathrm{CO}_{2}$ transport based on observed winds, 4, Mean annual gradients and interannual variations, in Aspects of Climate Variability in the Pacific and the Western Americas, edited by D. H. Peterson, AGU, Washington, D. C., 1989b.

Maier-Reimer, E., and K. Hasselmann, Transport and storage of $\mathrm{CO}_{2}$ in the ocean-an inorganic ocean-circulation carbon cycle model, Clim. Dyn., 2, 63-90, 1987.

Marland, G., and R. M. Rotty, Carbon dioxide emissions from fossil fuels: A procedure for estimation and results for 1950-1982, Tellus, $36 B, 232-261,1984$.

McFarlane, N. A., The effect of orographically excited gravity wave drag on the general circulation of the lower stratosphere and troposphere, J. Atmos. Sci., 44, 1775-1800, 1987.

Melillo, J. M., A. D. McGuire, D. W. Kicklighter, B. Moore III, C. J. Vorosmarty, and A. L. Schloss, Global climate change and terrestrial net primary production, Nature, 363, 234-240, 1993.

Mueller, J. F., Geographical distribution and seasonal variation of surface emissions and deposition velocities of atmospheric trace gases, J. Geophys. Res., 97, 3787-3804, 1992.

Pearman, G. I., and D. J. Beardsmore, Atmospheric carbon dioxide measurements in the Australian region: Ten years of aircraft data, Tellus, 36, 1-24, 1984 .

Pearman, G. I., and P. Hyson, Global transport and inter-reservoir exchange of carbon dioxide with particular reference to stable isotopic distributions, J. Atmos. Chem., 4, 81-124, 1986.

Phillips, L. F., $\mathrm{CO}_{2}$ transport at the air-sea interface: Effect of coupling of heat and matter fluxes, Geophys. Res. Lett., 18, 1221-1224, 1991

Quay, P. D., B. Tilbrook, and C. S. Wong, Oceanic uptake of fossil fuel $\mathrm{CO}_{2}$ : Carbon-13 evidence, Science, 256, 74-79, 1992.

Rasch, P. J., and D. L. Williamson, Computational aspects of moisture transport in global models of the atmosphere, $Q$. J. R. Meteorol. Soc., $116,1071-1090,1990 \mathrm{a}$.

Rasch, P. J., and D. L. Williamson, On shape-preserving interpolation and semi-Lagrangian transport, SLAM J. Sci. Stat. Comput., 11, 656687, $1990 \mathrm{~b}$.

Rasch, P. J., and D. L. Williamson, The sensitivity of a general circulation model climate to the moisture transport formulation, $J$. Geophys. Res., 96, 13,123-13,137, 1991.

Raynaud, D., J. Jouzel, J. M. Barnola, J. Chappellaz, R. J. Delmas, and C. Lorius, The ice record of greenhouse gases, Science, 259, 926934, 1993.

Revelle, R, and H. E. Suess, Carbon dioxide exchange between atmosphere and ocean, and the question of an increase of atmospheric $\mathrm{CO}_{2}$ during the past decades, Tellus, 9, 18-27, 1957.

Rotty, R. M., A look at $1983 \mathrm{CO}_{2}$ emissions from fossil fuels (with preliminary data for 1984), Tellus, 39B, 203-208, 1987a.

Rotty, R. M., Estimates of seasonal variation in fossil fuel $\mathrm{CO}_{2}$ emissions, Tellus, 39B, 184-202, 1987b. 
Sarmiento, J. L. and E. T. Sundquist, Revised budget for the oceanic uptake of anthropogenic carbon dioxide, Nature, 356, 589-593, 1992.

Shea, D. J., K. E. Trenberth, and R. W. Reynolds, A global monthly sea surface temperature climatology, NCAR Tech. Note, NCAR/TN345+STR, 167 pp., Nat. Cent. for Atmos. Res., Boulder, Colo. 1990.

Slingo, J. M., The development and verification of a cloud prediction scheme for the ECMWF model, $Q$. J. R. Meteorol. Soc., 113, 899$927,1987$.

Tanaka, M., T. Nakazawa, S. Aoki, Time and space variations of tropospheric carbon dioxide over Japan, Tellus, 39, 3-12, 1987.

Tans, P.P., I. Y. Fung, and T. Takahashi, Observational constraints on the global atmospheric $\mathrm{CO}_{2}$ budget, Science, 247, 1431-1438, 1990.

Thoning, K. W., P. P. Tans, and W. D. Komhyr, Atmospheric carbon dioxide at Mauna Loa Observatory, 2, Analysis of the NOAA GMCC data, 1974-1985, J. Geophys. Res., 94, 8549-8565, 1989.

Troen, I., and L. Mahrt, A simple model of the atmospheric boundary laryer; Sensitivity to surface evaporation, Boundary-Layer Meteorol., $37,129-148,1986$

Watson, A. J., C. Robinson, J. E. Robinson, P. J. le B. Williams, and M. J. R. Fasham, Spatial variability in the sink for atmospheric carbon dioxide in the North Atlantic, Nature, 350, 50-53, 1991.

Weiss, R. F., Carbon dioxıde in water and seawater: The solubility of a non-ideal gas, Marine Chem., 2, 203-215, 1974.

Williamson, D. L., and P. J. Rasch, Two-dimensional semi-Lagrangian transport with shape preserving interpolation, Mon. Weath. Rev., 117, 102-129, 1989.
Wong, C. S., and Y.-H. Chan, Temporal variations in the partial pressure and flux of $\mathrm{CO}_{2}$ at ocean station $\mathrm{P}$ in the subarctic northeast Pacific Ocean, Tellus, 43B, 206-223, 1991.

Woodwell, G. M., J. E. Hobbie, R. A. Houghton, J. M. Melillo, B. Moore, B. J. Peterson, and G. R. Shaver, Global deforestation: Contribution to atmospheric carbon dioxide, Science, 222, 1081-1086, 1983.

\section{P. Ciais, LMCE, Gif-sur-Yvette, France.}

D. J. Erickson (corresponding author), C. A. Fischer, and S. Walters, Atmospheric Chemistry Division, National Center for Atmospheric Research, PO Box 3000, Boulder CO 80307-3000. (e-mail: erickson@ucar.edu; fischer@ucar.edu; stacy@ucar.edu).

P. Friedlingstein, Belgian Institute for Space Aeronomy, Brussels, Belgium.

E. Maier-Reimer and K. Six, Max-Planck-Institut Für Meteorologie, Hamburg, Germany.

P. J. Rasch, Climate and Global Dynamics Division, National Center for Atmosphenc Research, PO Box 3000, Boulder CO 80307-3000. (email: pjr@ucar.edu)

P.P. Tans, NOAA Climate Monitoring and Diagnostics Laboratory, 325 Broadway, Boulder, CO, 80303. (e-ma1l: ptans@cmdl. noaa.gov)

(Received May 16, 1995; revised November 15, 1995; accepted November 15, 1995.) 